\title{
Probabilistic modelling of forces of hail
}

\author{
Shihara Perera ${ }^{a}$ \\ ${ }^{a}$ Department of Infrastructure Engineering, The University of Melbourne
} Parkville, VIC, 3010, Australia. shiharap@student.unimelb.edu.au +61 450737336 (Corresponding Author- ORCID: 0000-0002-2922-0344) Nelson Lam ${ }^{\mathrm{b}}$

${ }^{\mathrm{b}}$ Department of Infrastructure Engineering, The University of Melbourne Parkville, VIC, 3010, Australia. ntkl@unimelb.edu.au

\begin{abstract}
Mahil Pathirana ${ }^{\mathrm{c}}$
${ }^{c}$ Department of Infrastructure Engineering, The University of Melbourne Parkville, VIC, 3010, Australia.dpathirana@student.unimelb.edu.au
\end{abstract}

\section{Lihai Zhang ${ }^{\text {d }}$}

${ }^{\mathrm{d}}$ Department of Infrastructure Engineering, The University of Melbourne Parkville, VIC, 3010, Australia. lihzhang@unimelb.edu.au

\section{Dong Ruan ${ }^{\mathrm{e}}$}

${ }^{\mathrm{e}}$ Faculty of Science, Engineering and Technology, Swinburne University of Technology Hawthorn, VIC, 3122, Australia. druan@swin.edu.au

\section{Emad Gad}

${ }^{\mathrm{f}}$ Faculty of Science, Engineering and Technology, Swinburne University of Technology Hawthorn, VIC, 3122, Australia. egad@swin.edu.au 


\begin{abstract}
Numerical modelling techniques enable forcing function at the point of contact in a hail impact to be predicted but many models available in commercial software have not been verified by experiments. A recently developed deterministic model is only able to simulate the impact action of an idealised spherical hailstone. Results recorded from the impact testing of non-spherical simulated hail ice specimens show wide scatters and are different to spherical specimens. A stochastic model has been developed in this study to incorporate the variability of the modelling parameters representing the behaviour of non-spherical ice specimens and to generate time-histories of contact force for given impact scenarios. A probabilistic model which was developed previously to provide predictions of the distribution of the size of hailstones in a severe category hailstorm has also been further developed to provide predictions of the maximum contact force values in probabilistic terms. For any given predefined forcing function denting into the surface of a steel plate can be estimated by finite element analysis or experimentally on a test machine. The new knowledge base introduced in this paper can be used by manufacturers and designers to re-assess existing products and in making improvements to future installations taking into account cost benefits considerations.
\end{abstract}

Keywords: hailstone; contact force; forcing function; probabilistic; deterministic.

\title{
1 Introduction
}

Building components ranging from roof claddings to glass facades need to be designed to resist impact actions by flying, or fallen, objects including hailstones and windborne debris in extreme weather conditions. At present, the performance of any part of a structure in response to impact actions is normally assessed through:

(i) Calculations based on energy principles

(ii) Simulations by the use of a finite element model

(iii) Pass/fail prototype testing

The process of impact of a solid object can be resolved into localised effects which is controlled by the contact force and the impulsive effects which is characterised by the global deflection demand of the impact (Perera et al. 2016). Common calculation methods found on energy principles only provide predictions for the reaction force (emulating the impulsive effects of the impact) and not the contact force which controls the piercing of the metal cladding or perforation of the glass pane. The amount of contact force generated by the impact at the point of contact between the impactor and the surface of the target is much higher than the reaction force because of interferences by the inertia forces. In theory, the amount of contact force generated by the impact is equal to the sum of the inertia and reaction forces. In practice, the magnitude of the contact force can be many times higher than that of the reaction force and lasts for only a few milliseconds. The deflection of the target (and the associated reaction force) evolves over a much longer duration which depends on the natural period of 
vibration of the structure in support of the target. The harder the impactor material the shorter the contact period and thus the greater the amplitude of the contact force in delivering a given amount of momentum delivered by the impact. Thus, the use of energy based principles on its own would not be able to model such important influences for providing realistic assessment of the impact induced damage.

Sophisticated finite element (FE) software can be used to simulate impact actions (Anghileri et al. 2005; Combescure et al. 2011; Olsson et al. 2013; Park and Kim 2010) of hail but there are uncertainties over which material model to select in the FE analysis for specifying the dynamic stiffness parameters of the hailstone, and the targeted structure. In addition, one of the major issue with those early hail FE modelling is that the execution of different material models in FE analysis could give considerably different results (Anghileri et al. 2005). The modelling of the contact force is always filled with uncertainties given the sensitivity of the amount of force generated by the impact (at the point of contact) to variations in the compressive modulus (ie. hardness) and geometrical properties of a piece of hailstone. The lack of data and viable means of making reliable predictions of the impact action represents a knowledge gap. Representative information in relation to such properties can only be obtained experimentally and such experiments would need to be repeated to allow for variability between impactor samples.

Standards have been put in place to prescribe experimental procedures for the capacity assessment of roofing materials in withstanding impact by hail. For example, ANSI FM 4473 is a standard for Impact Resistance Testing of Rigid Roofing Materials which specifies detailed requirements of the testing and reporting protocols but there are no requirements for interpreting the mechanics of failure (ANSI FM 4473 -Test Standard for Impact Resistance ). Documentation of observations from impact experiments is limited to pass / fail criteria based upon qualitative description of damage namely cracking, fracturing or denting (ANSI FM 4473 -Test Standard for Impact Resistance ; Flueler 2009; Marshall et al. 2004). This compliance approach to impact testing is common practice, and it contributes little to improving knowledge on the underlying impact action and its correlation with damage to the target. Information recorded from prototype testings has been very restrictive for it is specific to the impact scenario and target sample employed in the test setup. It has always been difficult to make generalisation of results recorded from adhoc physical experimentation. Limitations with current assessment methodologies as described are major obstacles in the development of effective, and reliable, strategy to mitigate damage.

It has been reported that a $50 \mathrm{~mm}$ diameter hailstone would be sufficient to create a dent on the surface of a metal cladding whereas a $90 \mathrm{~mm}$ diameter hailstone is expected to cause perforation. The threshold size of a piece of hailstone that would cause functional damage to metal roofing is estimated to be at around $62.5 \mathrm{~mm}$ (Gessler and Petty 2013). These are useful, and general, observations from the field but this type of information is not precise enough to give predictions of the performance of a 
specific design. A probabilistic model for characterising the size of hailstones in a severe storm has also been developed (Fraile et al. 2003; Shimek et al. 2011). But there is a lack of information for correlating the size of hailstone with details of the impact action and its damaging potential to a specific type of target.

Deterministic analytical solutions for hailstone impact have been derived from earlier investigations by the authors and co-workers based on testing of spherical simulated hail ice (SHI) specimens (Sun et al. 2015). The typical shape of small hailstones is close to that of the sphere but can be irregular (non-spherical) in shape with larger size hailstones in particular (Flueler 2009; Gessler and Petty 2013; Marshall et al. 2004). In spite of the difference, studies undertaken to date on hailstone impact have been based mainly on the considerations of spherical specimens only (Anghileri et al. 2005; Appleby-Thomas et al. 2011; Kim and Kedward 2000; Kim et al. 2003; Perera et al. 2016; Sharafi et al. 2013; Tippmann et al. 2013). As revealed by Combescure et al. (2011) the geometry of the impact is more significant rather than the microstructure of the ice when the permanent deformation (damage) of the target plate is considered. Therefore, further research should be undertaken on nonspherical specimens for modelling variability behaviour.

In view of limitations with previous investigations, the objective of this study is to develop a probabilistic model for estimating the amount of contact force generated by the impact of irregularly shaped hailstones based on results from testing of non-spherical SHI specimens and from stochastic simulations.

\section{Deterministic solution for hailstone impact (spherical specimens)}

Testing and modelling of hailstone impact have been commonly based on the use of spherical specimens so that results are easily reproducible. Forcing functions developed at the point of contact of spherical SHI specimens can be obtained by using:

i. Impact experimentation using a device for measuring contact force

ii. Numerical simulation using FE software such as program LS DYNA

iii. Simulation by the use of a 2DOF model

iv. Use of a closed form expression which provides estimate of the maximum amplitude of the contact force but without the time-history (refer Sun et al. (2015)).

Two-degree-of-freedom (2DOF) spring mass modelling is a technique that can fulfil the requirements of predicting time histories of target deflection and impact force, yet retaining simplicity (Lam et al. 2009; Yang et al. 2012b). Due to its inherent simplicity, the method can be implemented on user friendly EXCEL spread sheets which is essentially inexpensive and transparent to the user (Lam et al. 2009). Rigorous analyses based on the use of programs like LS-DYNA have the shortcomings of being in-transparent and hence difficult to scrutinise (along with limitations that have been outlined in the earlier part of the paper). Numerical simulations undertaken in this study for determining the 
values of the contact force generated by hail impact are based on the two-degree-of-freedom (2DOF) spring mass system.

The analytical model based on an idealised 2DOF system has been developed for modelling impact actions (Fig. 1a). The lumped mass representing the impactor is connected to the frontal spring of non-linear viscous elastic properties as defined by Eq. (1a) and Eq. (1b). The second lumped mass at the rear is connected to the support through a second spring. The hardness properties of the material which makes up the impactor or the surface of the target are represented by the value of the (frontal) spring constant whereas the displacement response behaviour of the target as a whole is controlled by the extension-shortening behaviour of the rear spring of the 2DOF system. Solution for the damping coefficient $D_{n}$ as defined by Eq. (1b) has been derived by the authors in a previous study (Perera et al. 2016; Sun et al. 2015). The simulated forcing function at the point of contact, $F_{c}(t)$, is of the form depicted in Fig. $1 \mathrm{~b}$.

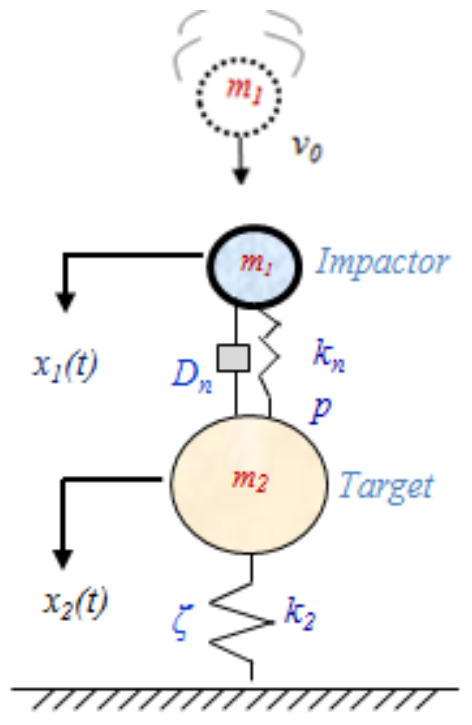

(a) 2DOF mass-spring system model behaviour

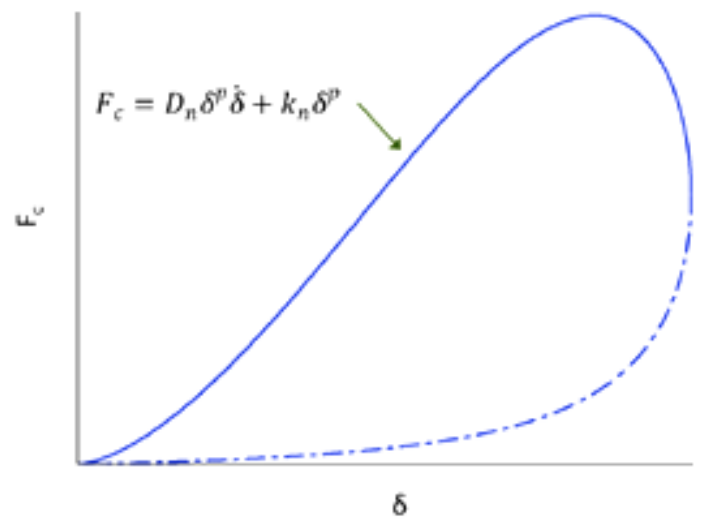

(b) Non-linear visco-elastic contact model behaviour

Fig. 1 2DOF spring-mass model with non-linear visco-elastic contact behaviour

$F_{c}(t)=D_{n} \delta^{p}(t) \dot{\delta}(t)+k_{n} \delta^{p}(t)$

where

$D_{n}=(0.2 p+1.3)\left(\frac{1-C O R}{C O R}\right) \frac{k_{n}}{\dot{\delta_{0}}}$

The value of $k_{n}$ and $p$ can be derived from experimental measurements of the contact force by a twostep calibration procedure as described in Sun et al. (2015) whereas the value of the coefficient of restitution $(C O R)$ can be inferred from the observed change in the relative velocity on rebounce of the hailstone specimen from the surface of the target (by high speed camera capture). If the hailstone disintegrates on impact with no rebounce occurring, $C O R \approx 0$. Results derived from the two-step calibration approach covering a range of impact velocities $\left(v_{0}\right)$ have been collated for linear regression 
analysis leading to Eq. $(2 \mathrm{a}-2 \mathrm{c})$ which provide best estimates of the parameter values for any given value of $v_{0}$ (Sun et al. 2015).
$k_{n}=2.202 v_{0}+170(\mathrm{kN} / \mathrm{m})$
$\left(R^{2}=0.85\right)$
Eq. (2a)
$p=0.01 v_{0}+1.27$
$\left(R^{2}=0.96\right)$
Eq. $(2 b)$
COR $=-0.001 v_{0}+0.049$
$\left(R^{2}=0.98\right)$
Eq. $(2 c)$

Eqns.(1a) - (2c) enable time-history (ie. forcing functions) of the contact force to be predicted conveniently. However, the relationships for $k_{n}, p$ and COR presented in Eq.2a $-2 \mathrm{c}$ are valid only for hailstones impacting on a steel (or on a metallic) surface. It is noted that the stated relationships may not be applicable should the surface of the target be made of soft materials. Moreover, these equations are only valid for hailstones impacting on the target in the normal direction and at an impact velocity ranging between $10 \mathrm{~m} / \mathrm{s}-50 \mathrm{~m} / \mathrm{s}$.

The terminal velocity $\left(v_{T}\right)$ of a hailstone under gravity can be calculated using Eq. (3) (Paterson and Sankaran 1994).

$$
v_{T}=\sqrt{\frac{4 \rho_{\text {hail }} D_{\text {hail }} g}{3 \rho_{\text {air }} C_{D}}}
$$

where $g=9.81 \mathrm{~m} / \mathrm{s}^{2}$ and $D_{\text {hail }}$ is the equivalent mass diameter of the hailstone. The value of hail density $\left(\rho_{\text {hail }}\right)$ and air density $\left(\rho_{\text {air }}\right)$ can be taken as $890 \mathrm{~kg} / \mathrm{m}^{3}$ and $1.2 \mathrm{~kg} / \mathrm{m}^{3}$ respectively. The drag coefficient $\left(C_{D}\right)$ is characterised by the shape of the hailstone. A smooth perfectly spherical shaped hailstone would have a $C_{D}$ of approximately 0.5 whereas a rougher and irregular-shaped hailstone would theoretically increase drag and, thus would have $C_{D}$ of 0.8 or even larger (Matson and Huggins 1980).

For example, the contact force value generated by the impact of a $50 \mathrm{~mm}$ dia. spherical hailstone specimen weighting $59.5 \mathrm{~g}$ at an impact velocity of $28.5 \mathrm{~m} / \mathrm{s}$ (calculated from Eq. 3) is to be predicted. The hysteretic properties of the frontal spring forming part of the 2DOF system is defined by Eq. (1) and shown by the schematic diagram of Fig. 2 . The value of $k_{n}=233 \mathrm{kN} / \mathrm{m}, p=1.55$ and $C O R=0.02$ can be found using Eqns. (2a) - (2c). The quoted value of $m_{2}=2.164 \mathrm{~kg}$ and $k_{2}=53.32$ $\mathrm{kN} / \mathrm{m}$ are equipment parameters of the custom made apparatus for measuring contact force (the details of which are presented in the later part of the paper). In practice, the value of the lumped mass and the stiffness of the target structure can be found using standard structural dynamics techniques. For example, the value of the lumped mass representing a simply supported beam is $50 \%$ of the total mass of the beam whereas the stiffness of the rear spring is simply the static stiffness (being $48 \mathrm{EI} / \mathrm{L}^{3}$ ). Given the governing equations the values of parameters characterising the 2DOF system can be calculated by the use of common row and column operations on spread sheets (refer Appendix A for a demonstration of the calculation procedure). 


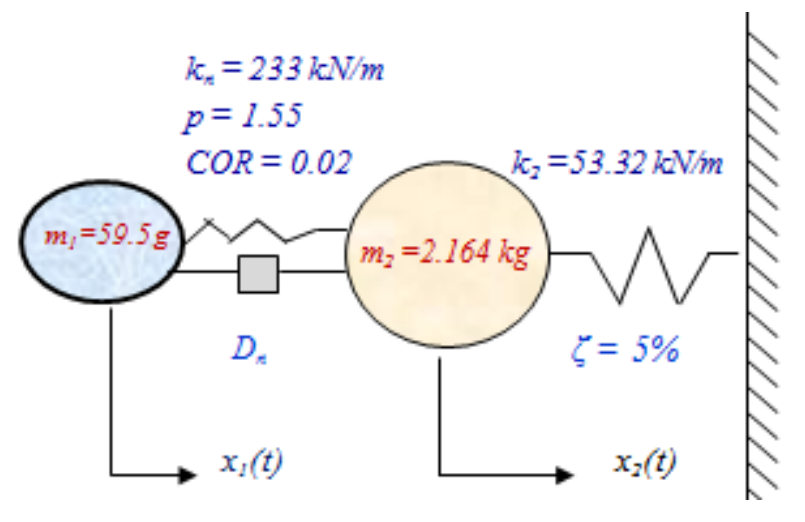

Fig. 2 Representation of $50 \mathrm{~mm}$ diameter hailstone impacting at $28.5 \mathrm{~m} / \mathrm{s}$ in $2 \mathrm{DOF}$ model

The simulated time-histories of the reaction force and the contact force are shown in Fig. 3a and Fig. $3 \mathrm{~b}$ to match with the measured time-histories. Thus, the model of Fig. 1 and Fig. 2 have been verified experimentally. It is noted that the mass and stiffness properties (value of the rear spring constant) of the structure in support of the target have negligible influence on the behaviour of the localised contact force because of the "short lived" nature of the transient action even though there can be significant influence of these properties on the impulsive action (displacement response behaviour of the target) of the impact(Sun et al. 2015; Yang et al. 2012a; Yang et al. 2012b). Thus, solutions to the contact force as presented herein are robust because of their insensitivity to the behaviour of the targeted object.
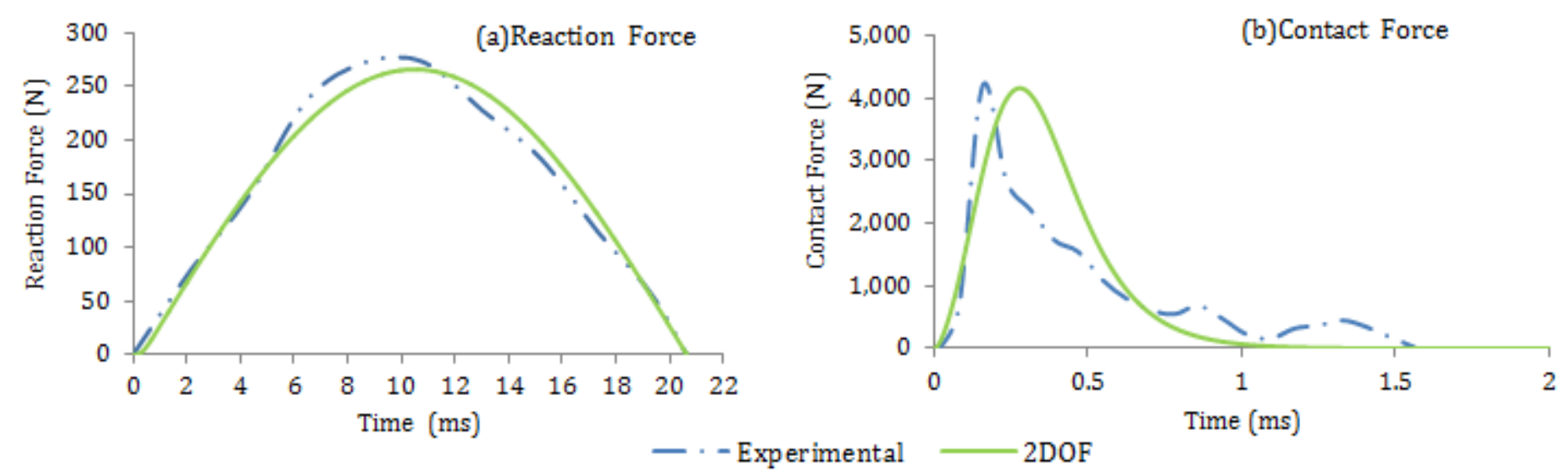

Fig. 3 Simulated impact responses by $50 \mathrm{~mm}$ dia. hailstone at $28.5 \mathrm{~m} / \mathrm{s}$ using $2 \mathrm{DOF}$ model

\section{Stochastic modelling of hailstone impact (non-spherical specimens)}

\subsection{Impact experiments}

The investigation to be reported in the rest of this paper involved measuring and modelling impact forces that were generated by impact of spherical and non-spherical hailstones. Given that actual hailstones occurring in nature are difficult to collect and preserve, laboratory produced simulated hail ice (SHI) specimens were used. The consistent fabrication of SHI is required for the repeatability of the experimental results. Non-spherical (irregular) and spherical shaped ice projectiles (Fig. 4) were 
made using a series of split moulds having a filling hole. Water was filled to the cavity through the filling hole using a syringe. A $55 \mathrm{~mm}$ diameter spherical ice specimen weighed $77 \mathrm{~g}$ whereas irregular shaped ice projectile weighed $75 \mathrm{~g}$ (Fig. 4). The cast ice impactors were kept frozen at a temperature of $-26{ }^{\circ} \mathrm{C}$ (Kim et al. 2003).

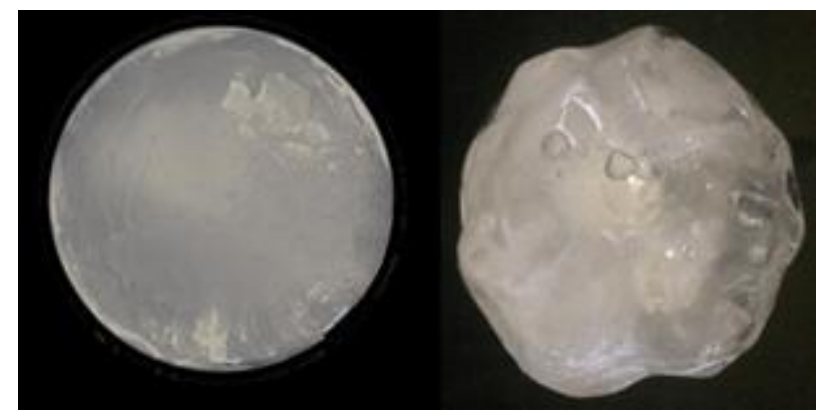

Fig. 4 Spherical and non-spherical SHI

The equivalent mass diameter of the tested non-spherical ice specimen can be taken as approximately $55 \mathrm{~mm}$. By substituting $D_{\text {hail }}=55 \mathrm{~mm}$ and $C_{D}=0.8$ into Eq. (3) the terminal velocity of a nonspherical ice specimen may be taken to be $25.8 \mathrm{~m} / \mathrm{s}$. However, a piece of hailstone generally does not fall straight down but rather has a horizontal motion component that is resulted from wind pressure. Thus, the design impact velocity of falling hailstones should be taken as the vector sum of the free-fall (terminal) component and the horizontal motion (wind) component (Gessler and Petty 2013). To ensure that impact tests conducted represent real conditions another four impact velocities (being 30.5 $\mathrm{m} / \mathrm{s}, 36 \mathrm{~m} / \mathrm{s}, 39.8 \mathrm{~m} / \mathrm{s}$, and $45.4 \mathrm{~m} / \mathrm{s}$ ) have been included in the testing program to allow for the combined actions of gravity and wind.

A custom made measuring device (Fig. 5) has been made-up by the authors and co-worker for measuring the amount generated contact force value by an impact. The fundamental operational principle of the measurement device is to incorporate a physical model of a spring connected lumped mass system within the device in order that the time history of the contact force can be inferred from the directly measured time-histories of the lumped mass and the rear spring. The value of the contact force can be calculated as the sum of the reaction force (deduced from the retraction of the supporting spring which is measured by laser sensor) and the inertial force generated from within the targeted mass (deduced from the accelerations of the lumped mass which is measured by the attached accelerometer). Detailed descriptions of this innovative (custom designed) apparatus for measuring contact force can be found in two published journal articles of the authors (Perera et al. 2016; Sun et al. 2015). 


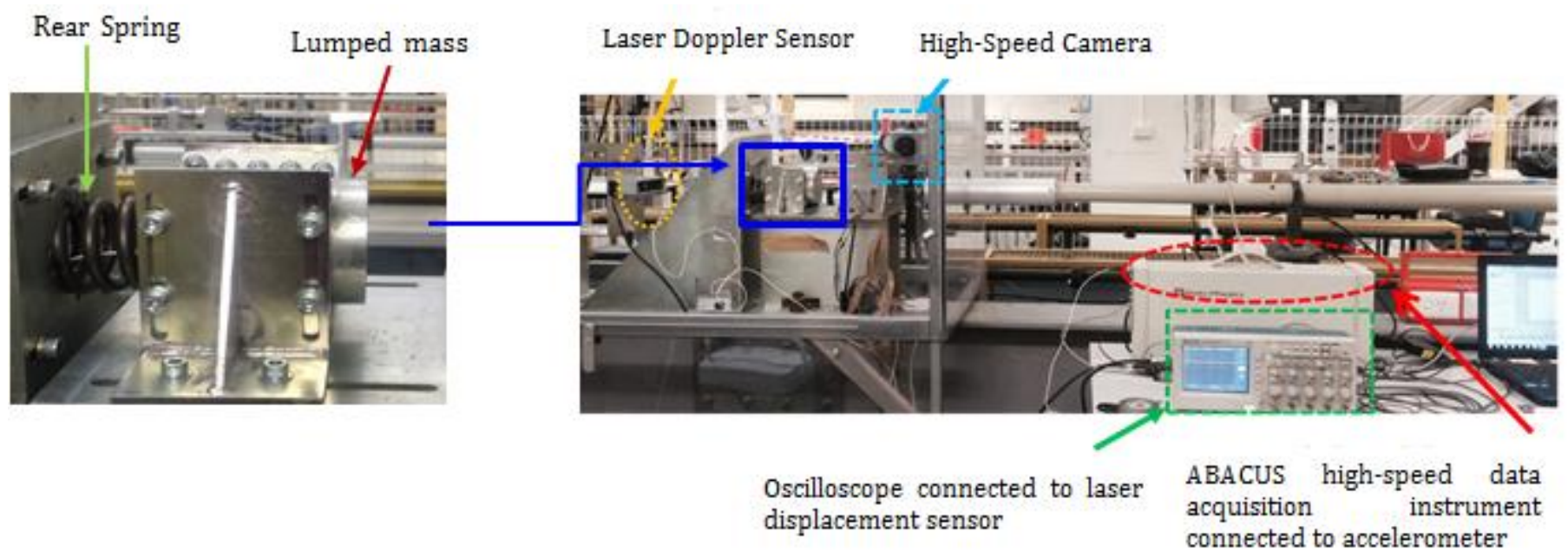

Fig. 5 Experimental Set up and Instrumentation

\subsection{Results and Discussion}

It is shown in experiments undertaken by the authors that for a given mass and velocity the shape of the hailstone has minimal effects on the impact generated reaction force which controls the deflection of the target (Fig. 6). However, variations in the generated contact force value by non-spherical specimens from that generated by spherical specimens are clearly noticeable from experimental measurements (Fig. 7).

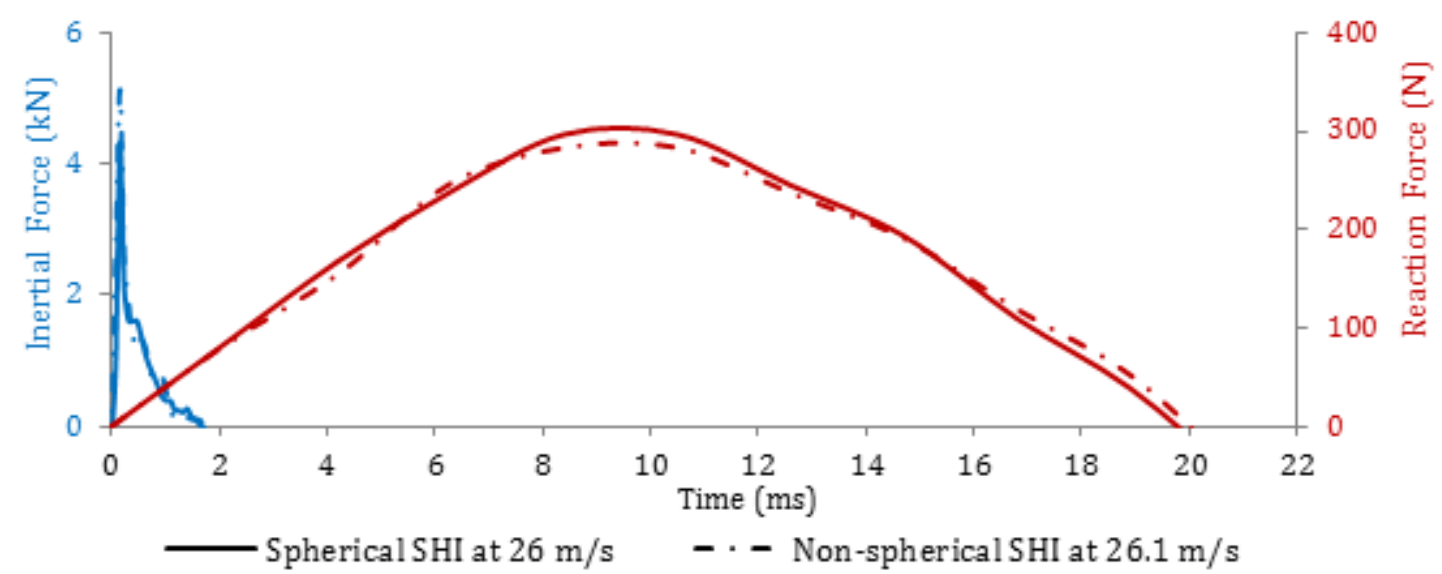

Fig. 6 Inertia and reaction forces generated by Spherical SHI and Non-spherical SHI at impact velocity approximately $26 \mathrm{~m} / \mathrm{s}$ 


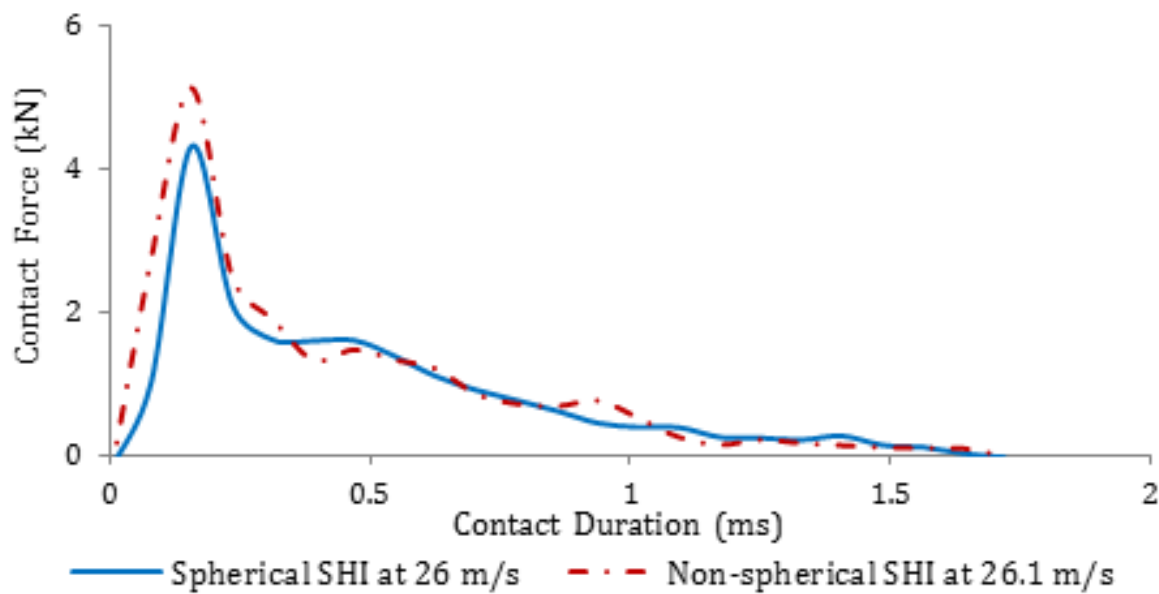

Fig. 7 Generated contact forces by spherical and non-spherical ice SHI specimens at impact velocity

approximately $26 \mathrm{~m} / \mathrm{s}$

Research published to date in the literature based on considering spherical hailstone specimens are not sufficient to fully characterise contact force behaviour of hail impact. Nonetheless, the peak contact force values generated by spherical and irregularly shaped hailstone specimens (based on averaging results across a large number of test) have been found to be highly consistent (Fig. 8a - Fig. 8e \& Appendix B). Thus, deterministic analytical, or numerical, models based on the consideration of spherical specimens can be used to constrain the value of the mean contact force for given size of hailstone and velocity of impact. Importantly, variations from the mean have not been modelled until now.

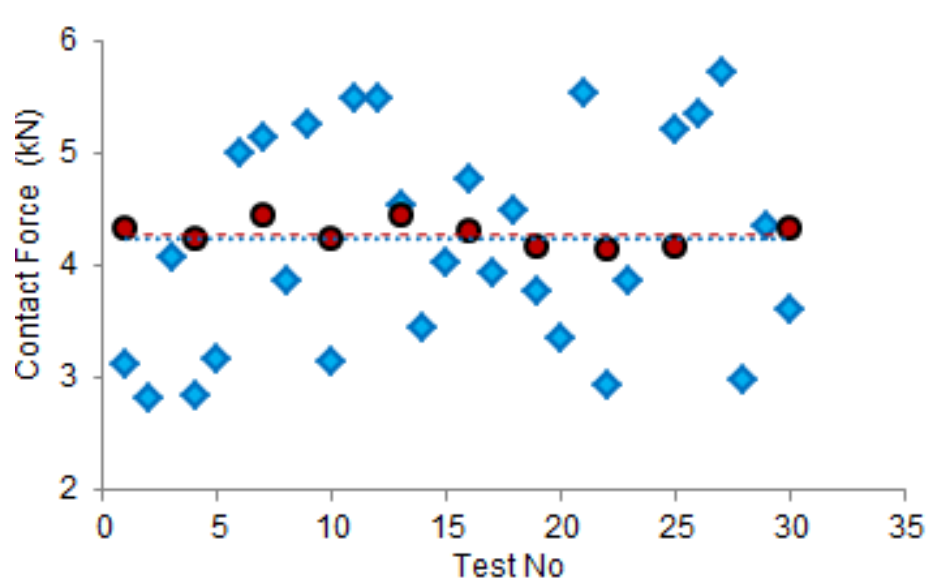

(a)

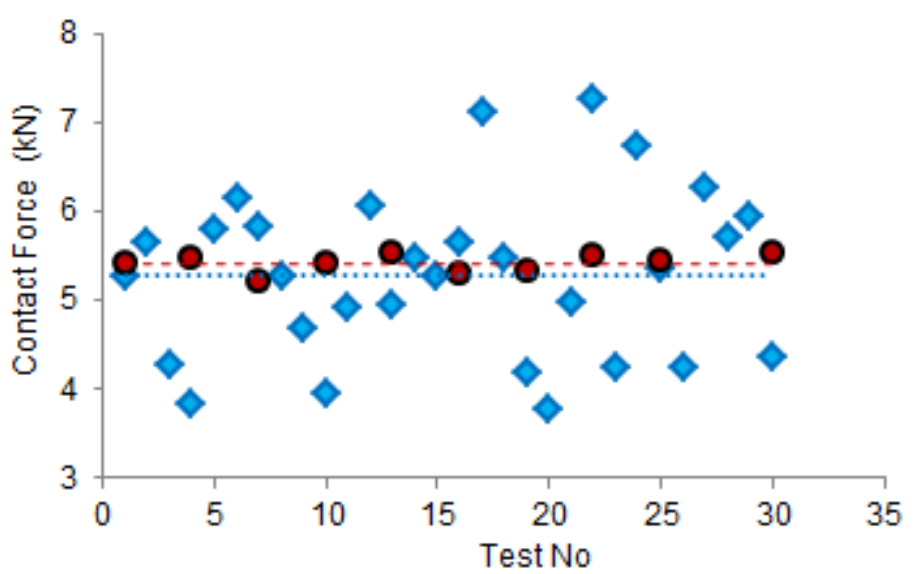

(b) 


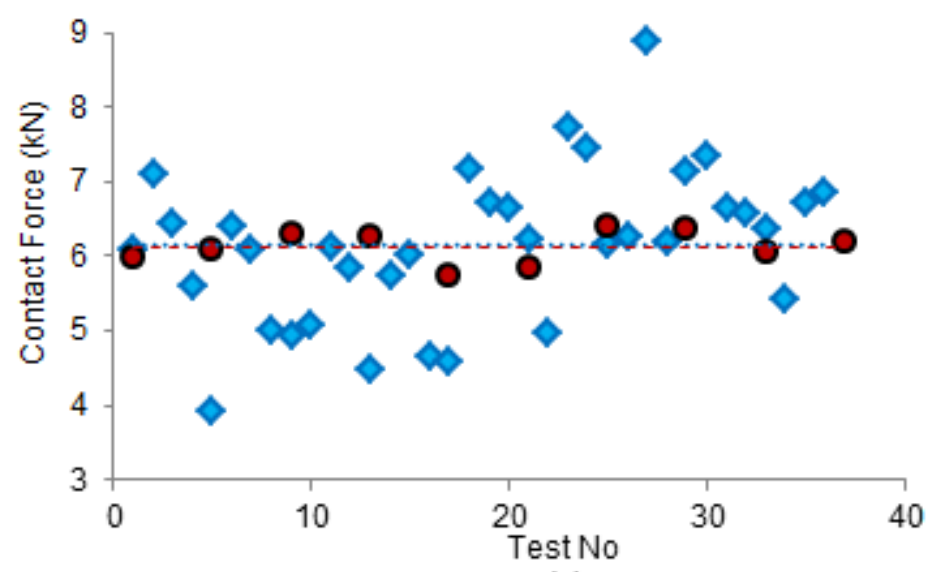

(c)

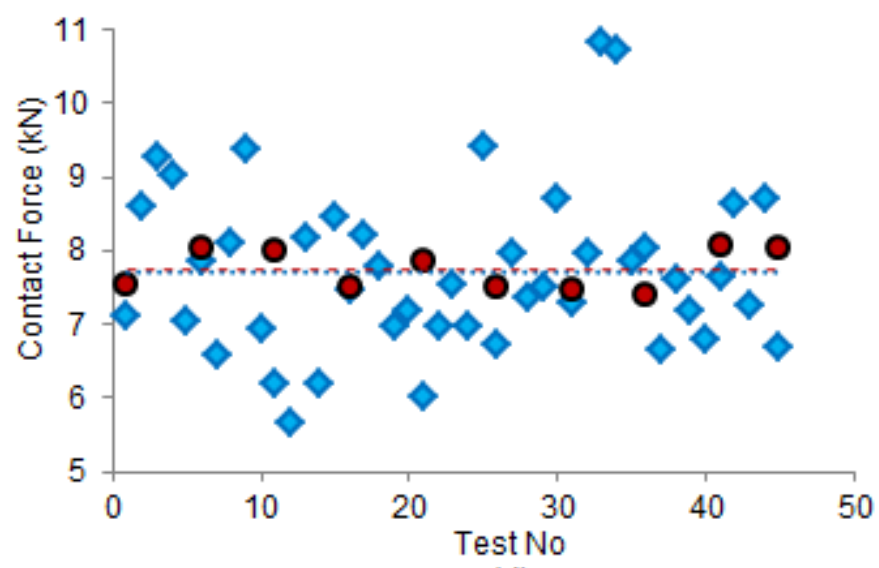

(d)

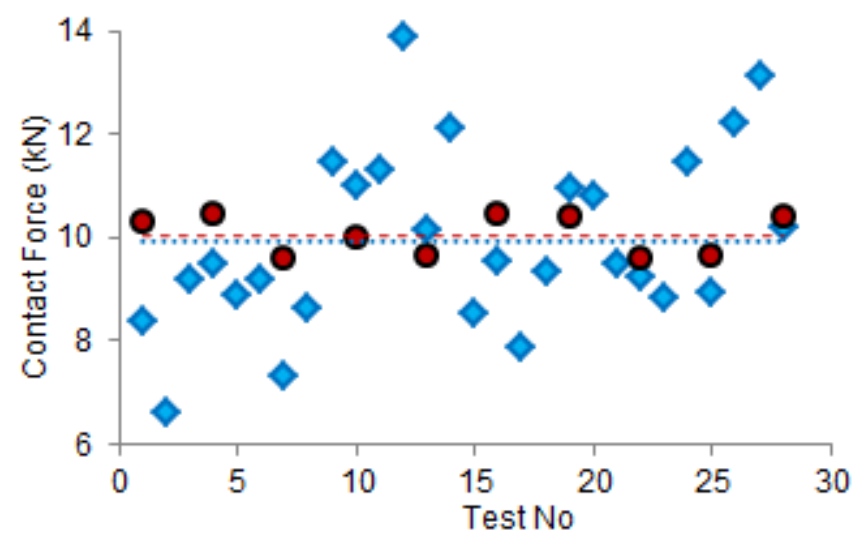

(e)

- Irregular Shaped Specimen

- Spherical Specimen

Mean of Irregular shaped Specimens

-..- Mean of spherical specimen

Fig. 8 Variation in contact force of non-spherical SHI specimens at different impact velocities (a) 25.7 $\mathrm{m} / \mathrm{s}$; (b) $30.5 \mathrm{~m} / \mathrm{s}$; (c) $36 \mathrm{~m} / \mathrm{s}$; (d) $39.8 \mathrm{~m} / \mathrm{s}$; (e) $45.4 \mathrm{~m} / \mathrm{s}$

The cumulative distribution of the (experimentally derived) contact force values (normalised with respect to the corresponding contact force value of a spherical hail ice specimen) was analysed, and presented in Fig. 9 to demonstrate good consistencies with the log-normal distribution relationship. All the measured values were within the range: $0.6-1.5$ times the mean. A zoom-in view at the upper (low frequency of exceedance) end of the probabilistic distribution further demonstrates that the lognormal distribution relationship is more consistent with measurements than the normal distribution relationship. 


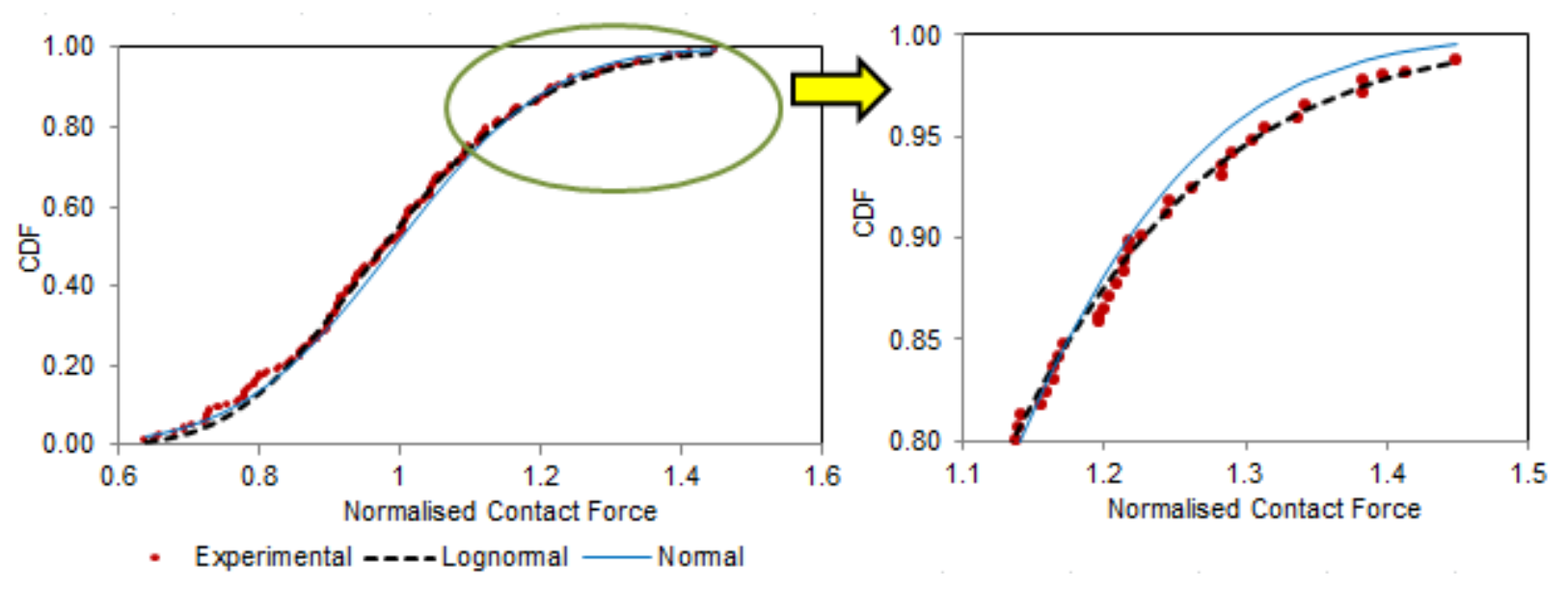

Fig. 9 Cumulative Distribution of normalised contact force for $55 \mathrm{~mm}$ equivalent diameter hailstone covering a range of impact velocities

Two degree-of-freedom (2DOF) system models of the form defined by Fig. 2 and Eqns. (1) \& (2) have been calibrated to match with experimental measurements. Values of parameters $k_{n}, p$ and $C O R$ characterising the 2DOF models were accordingly obtained for each individual recorded time-history of contact force generated by non-spherical hailstone specimens. It is shown that inter-specimen variability of the value of $k_{n}$ and $C O R$ for non-spherical specimens were much higher than spherical specimens, and particularly so for the $k_{n}$ parameter (Fig. 10a and Fig. 10c). In contrast, the value of $p$ was well constrained around the mean and there are no noticeable difference between results generated for non-spherical and spherical specimens (Fig. 10b). Thus, variation from the mean value of $p$ can be neglected. Empirical derived values of $k_{n}$ and COR were then curve-fitted by the normal and log-normal distribution relationships. It is shown that the distribution behaviour of $k_{n}$ is matched best by the log-normal distribution relationship (Fig. 11a) whereas the distribution behaviour of $C O R$ is matched best by the normal distribution relationship (Fig. 11b).

A stochastic model was then developed for simulating forcing function (time-history) at the position of contact based on parameter values defined by Eqns. (2a) - (2c) along with the identified lognormal distribution relationship of Fig. 11a (for parameter $k_{n}$ ) and the normal distribution relationship of Fig. 11b (for parameter COR). The parameter value for $p$ was taken as constant for a given impact velocity. Refer Table 1 for a summary. 
Table 1 Summary of stochastic model for hail impact

\begin{tabular}{ccc}
\hline Parameter & Deterministic solution & Probability Density Function (PDF) \\
\hline$k_{n}$ & $k_{\text {nsphere }}=2.202 v_{0}+170(k N / m)$ & $\frac{1}{0.32 k_{n} \sqrt{2 \pi}} \exp \left[-\frac{1}{2}\left(\frac{\ln k_{n}-\left(\ln k_{\text {nsphere }}-0.095\right)}{0.32}\right)^{2}\right.$ \\
$p$ & $p_{\text {sphere }}=0.01 v_{0}+1.27$ & no variations modelled \\
COR & COR $_{\text {sphere }}=-0.001 v_{0}+0.049$ & $\frac{1}{0.198 C O R_{\text {sphere }} \sqrt{2 \pi}} \exp \left[-\frac{1}{2}\left(\frac{\text { COR }- \text { COR }_{\text {sphere }}}{0.198 C O R_{\text {sphere }}}\right)^{2}\right]$ \\
\hline
\end{tabular}

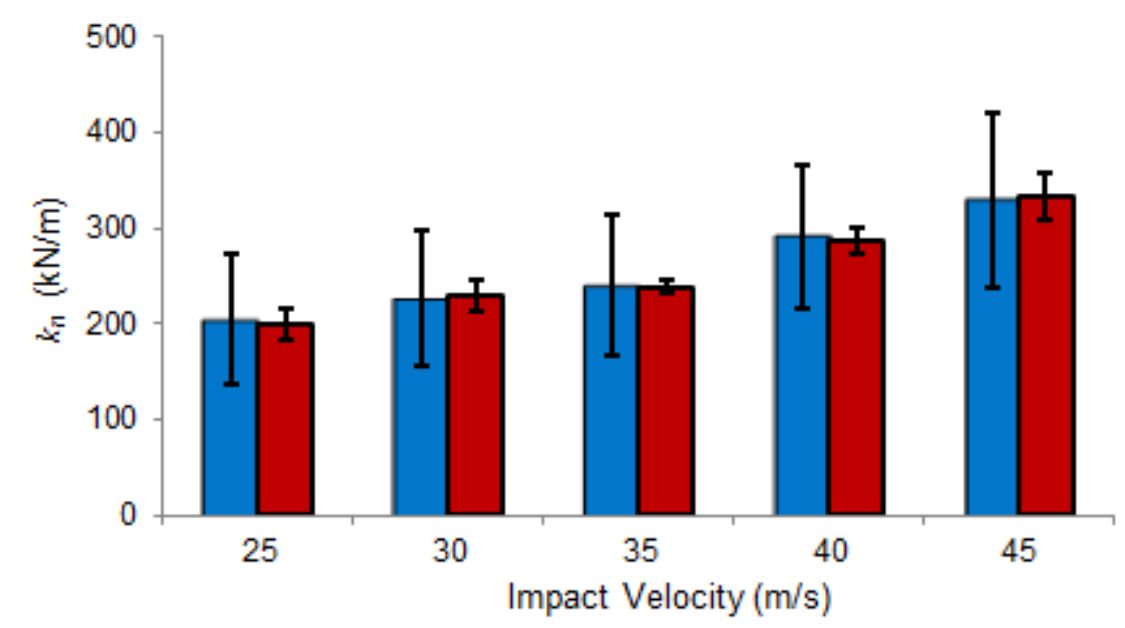

akn-Irregular-shaped SHI akn-Spherical SHI

(a)

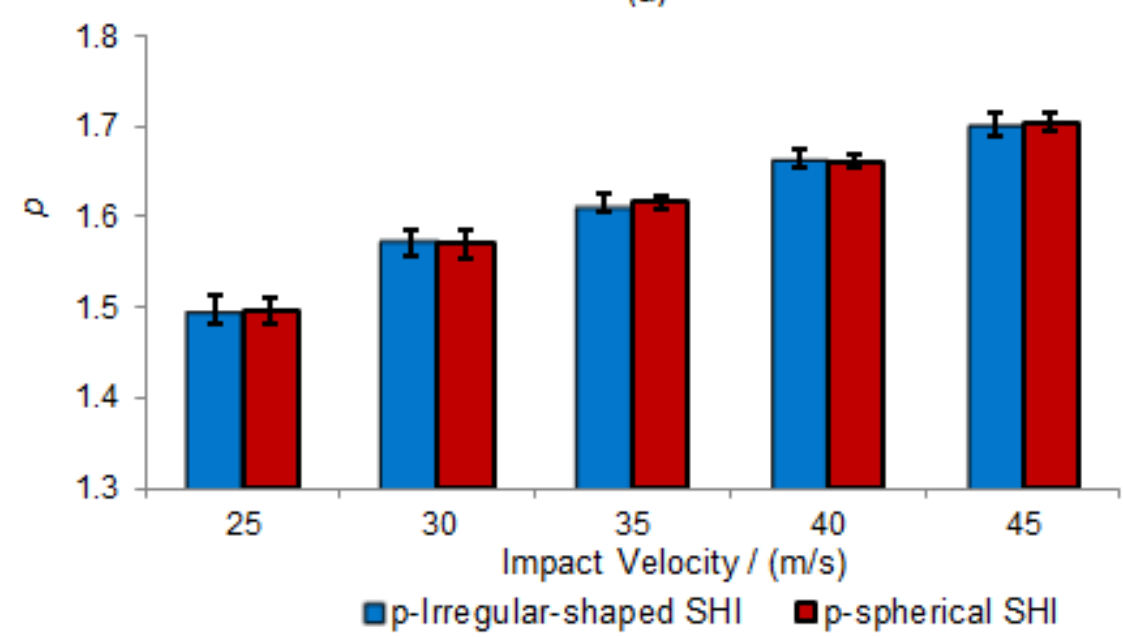

(b) 


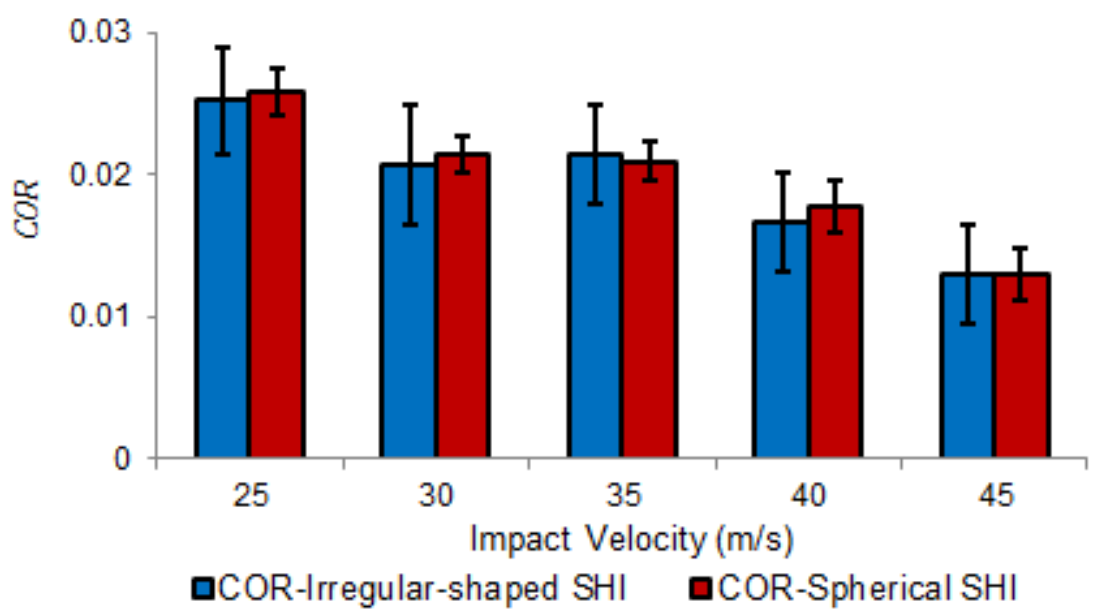

(c)

Fig. 10 Calibrated stiffness parameter values for SHI specimens (a) $k_{n}$; (b) $p$; and (c) measured $C O R$

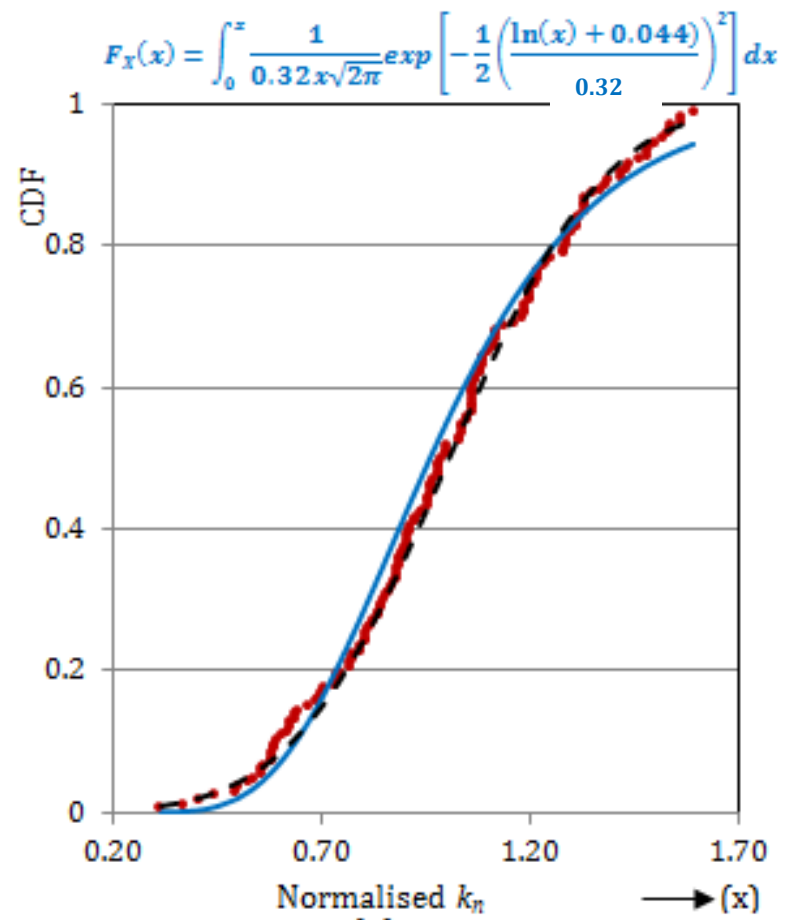

(a)

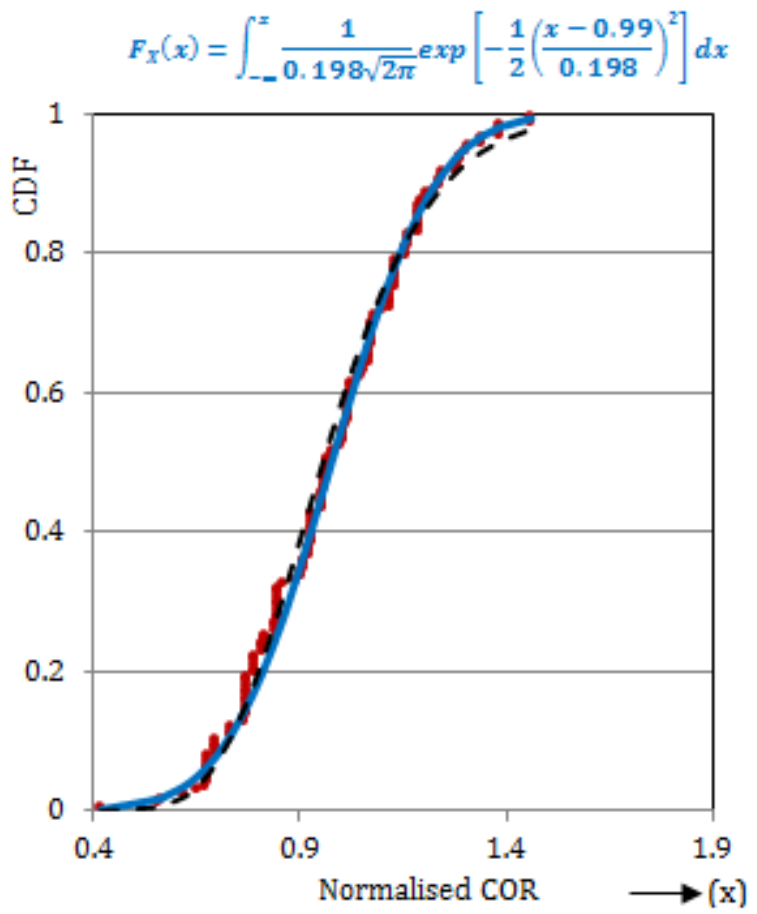

(b)

Fig. 11 Empirical CDFs of normalised (a) $k_{n}$; (b) COR for $55 \mathrm{~mm}$ dia. hailstone

A sample of 50 (out of a total of 5000 for the given impact scenario) randomly simulated values of $k_{n}$ and $C O R$ are presented in Fig. 12a - Fig. 12b along with the respective value of the deterministic solution as defined by Eqns. (2a) \& (2c) for the example impact scenario of a $50 \mathrm{~mm}$ equivalent diameter hailstone at an impact velocity of $28.5 \mathrm{~m} / \mathrm{s}$. The distribution behaviour of the stochastically simulated values of $k_{n}$ and $C O R$ are shown to be consistent with the experimentally derived relationships (Fig. 12c - Fig. 12d). Two example stochastically simulated sets of values of $k_{n}, p$ and COR were then used for constructing the respective forcing functions at the point of contact for comparison with the reference deterministic solution (of Fig. 3b) on the same figure (Fig. 13). 


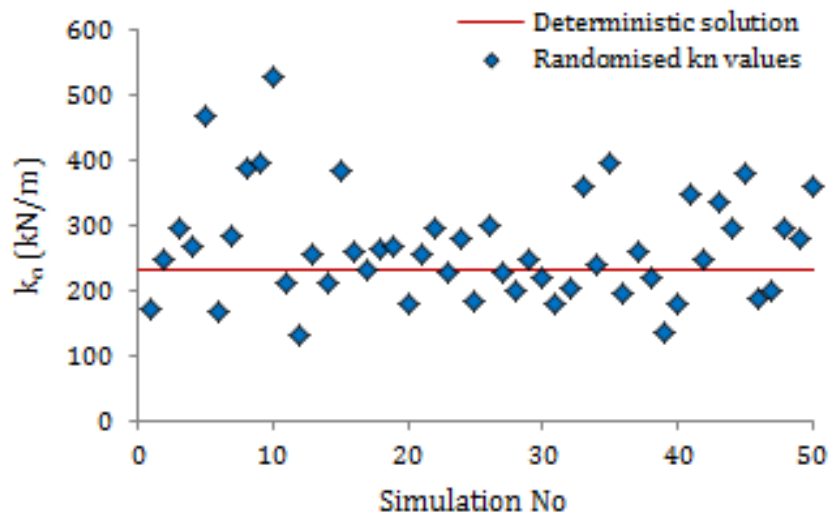

(a)

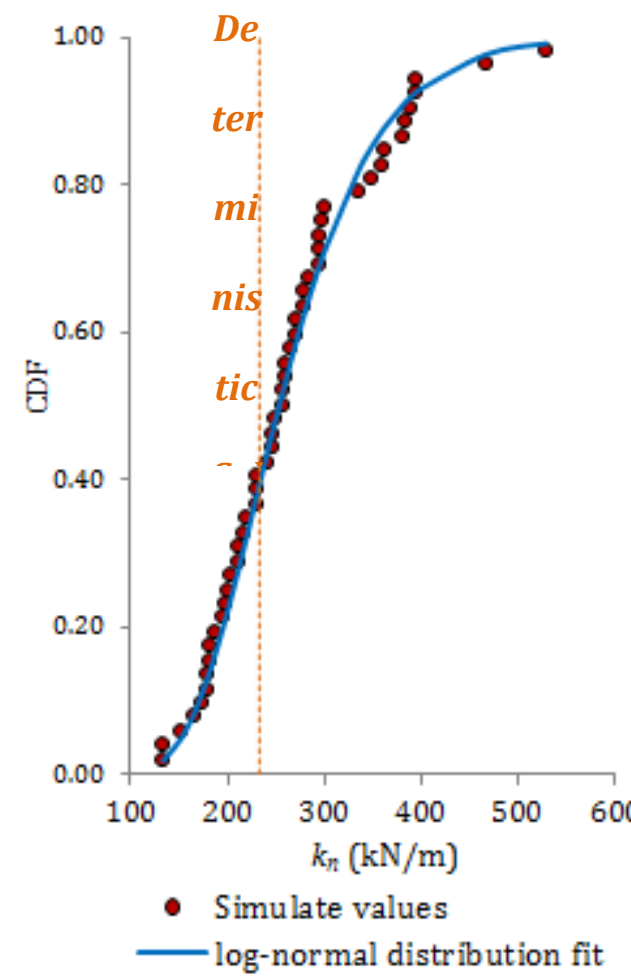

(c)

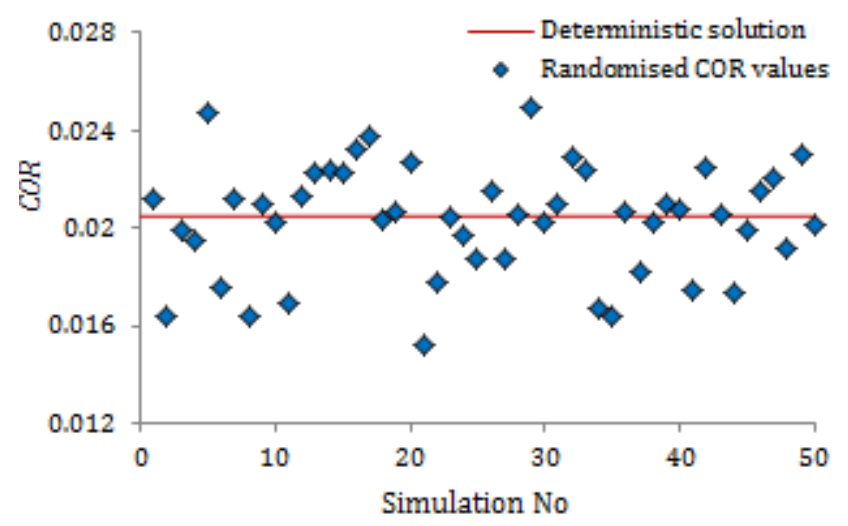

(b)

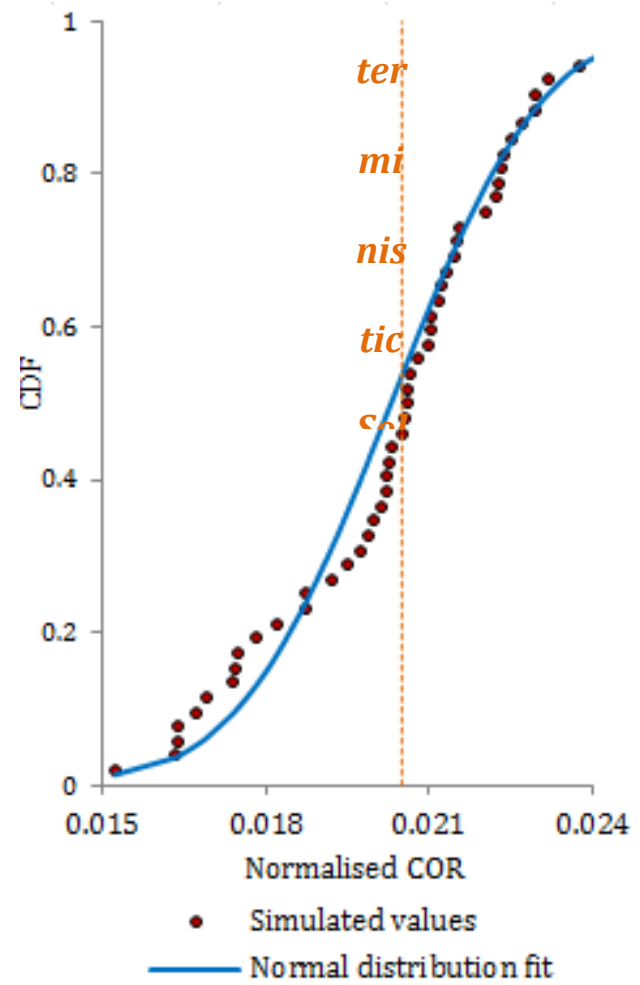

(d)

Fig. 12 A sample of 50 (out of a total of 5000) randomly simulated values of $k_{n}$ and COR for $50 \mathrm{~mm}$ equivalent dia. hailstone at an impact velocity of $28.5 \mathrm{~m} / \mathrm{s}$ 


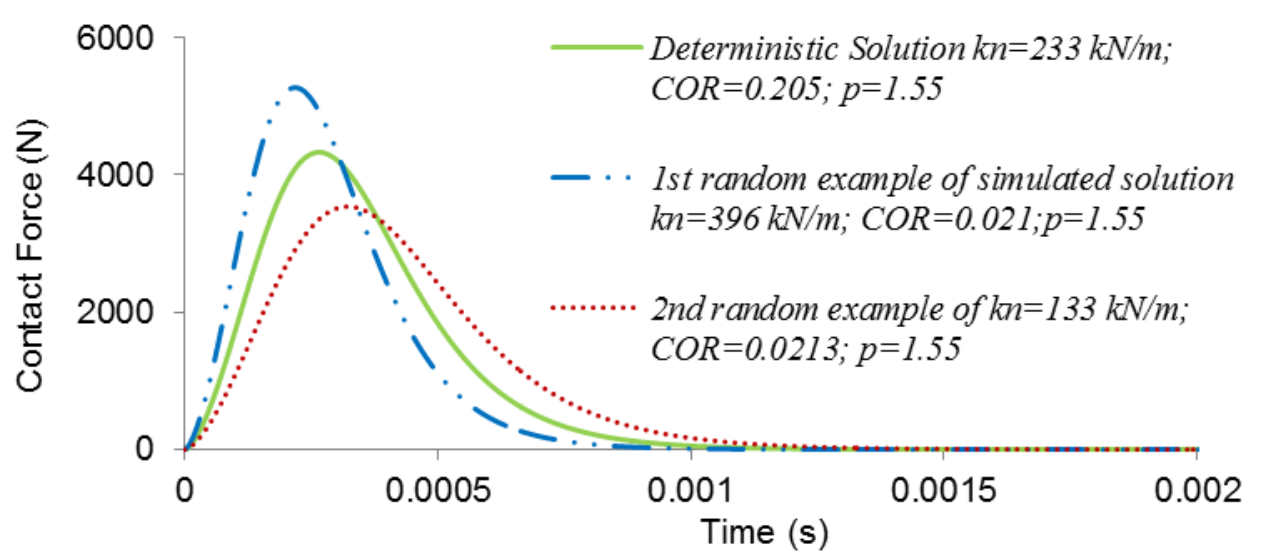

Fig. 13 Stochastically simulated versus deterministic forcing functions at point of contact

The stochastic model proposed herein as summarised in Table 1 was then verified by confirming that the $\mathrm{CDF}$ of the simulated, and experimentally measured, values of the maximum contact force were highly consistent in their probabilistic distribution. There were only minor discrepancies between the two databases of 5000 simulations across a number of impact scenarios. Fig. 14 shows good agreement between the two databases for the example impact scenario of $55 \mathrm{~mm}$ equivalent diameter hailstones at an impact velocity of $30.5 \mathrm{~m} / \mathrm{s}$.

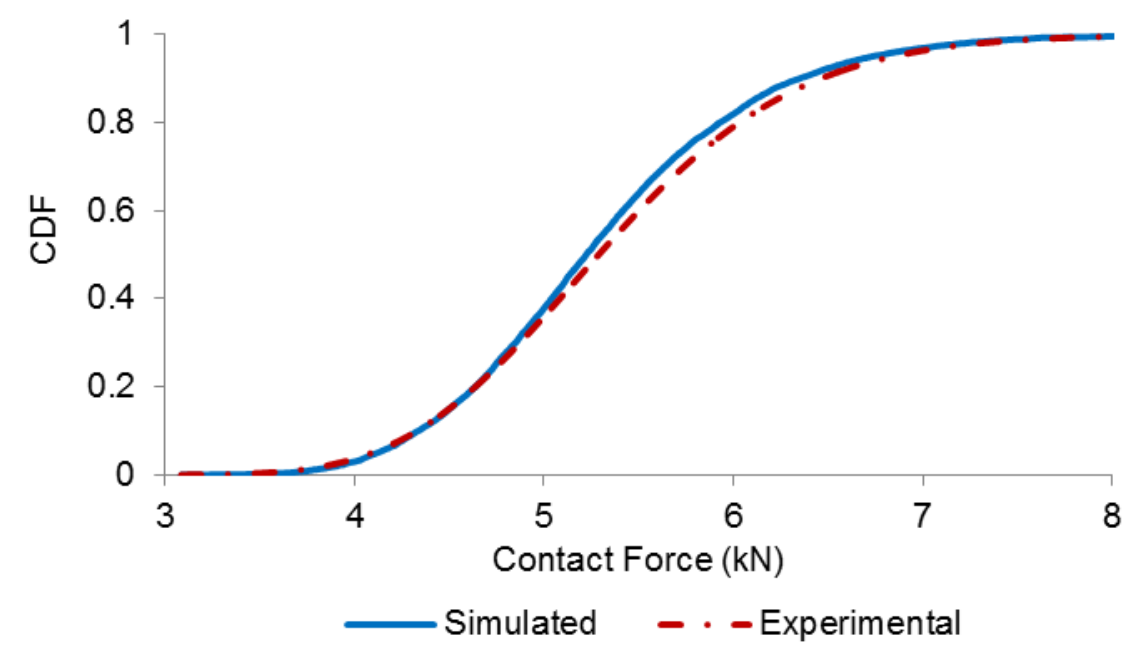

Fig. $14 \mathrm{CDF}$ of contact forces generated by $55 \mathrm{~mm}$ equivalent diameter hailstone at $30.5 \mathrm{~m} / \mathrm{s}$

The verification of the stochastic model enables empirical results recorded from experiments to be augmented by simulated values in order that even more robust probabilistic distribution relationships can be developed. Simulations have been repeated for impact by hailstones of different combinations (5000 simulations for each combination) of size and velocity (taken as the terminal velocity which is function of size). However, it is emphasized herein that the size effect has not been fully explored as it also influences the contact condition between the impactor and the target. Further, research is warranted to study the size effect. Results of the simulations are presented in probabilistic terms in Fig. 15 in which results associated with different percentiles of exceedance are shown. It is noted that predictions of the contact force from the probabilistic model for 50 percentile exceedance (ie. median 
predictions) are very consistent with predictions from the deterministic model (which was the trend demonstrated earlier in Fig. 8a - Fig. 8e). The probabilistic model is also presented in the alternative format of probabilistic density functions $(p d f)$ for specific impact scenarios. Design values corresponding to $5 \%$ of exceedance have been identified from the pdfs (Fig. 16a - Fig. 16c).

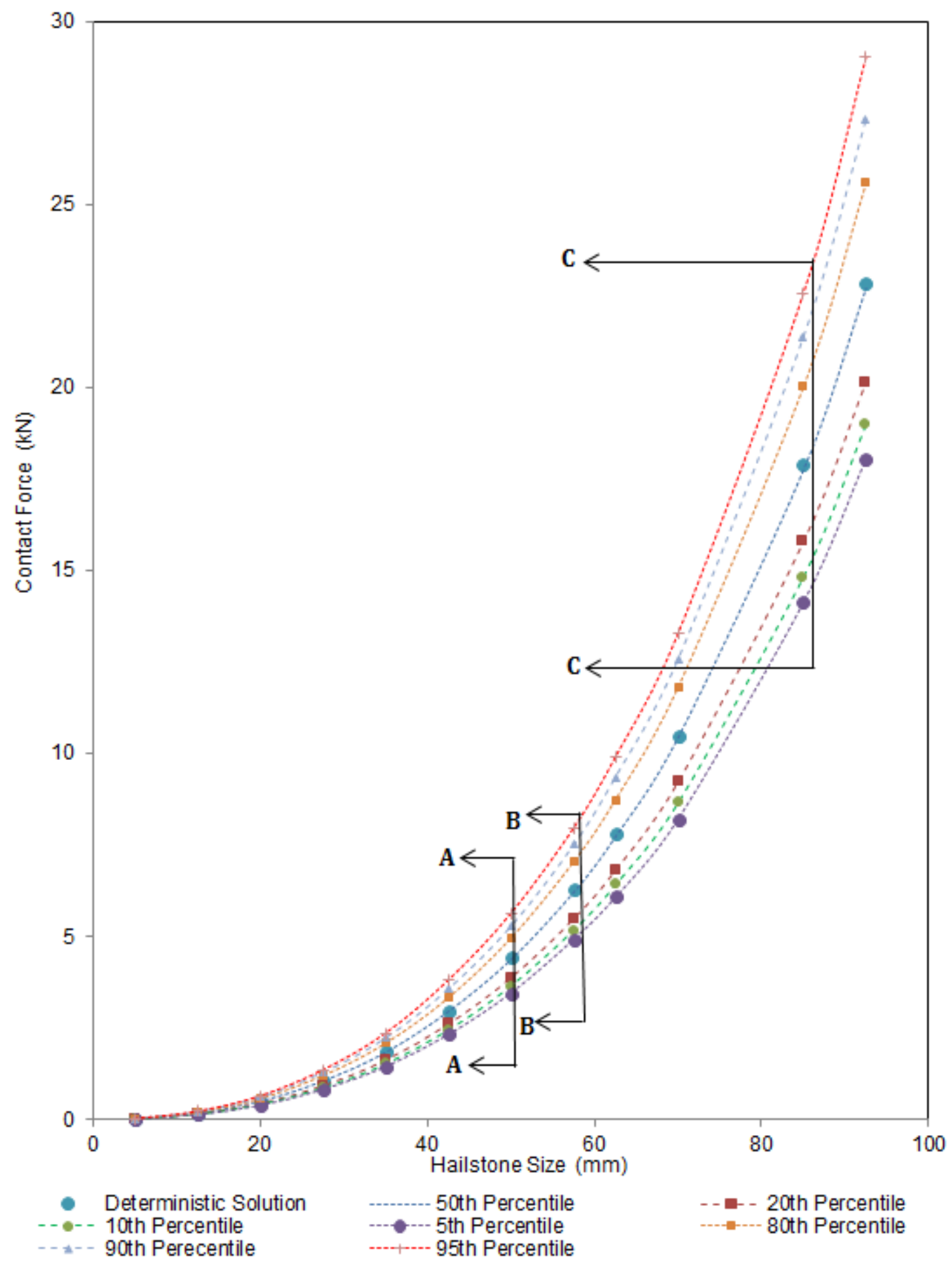

Fig. 15 Design chart presenting estimates of peak contact forces generated by hail incorporating the shape effects 


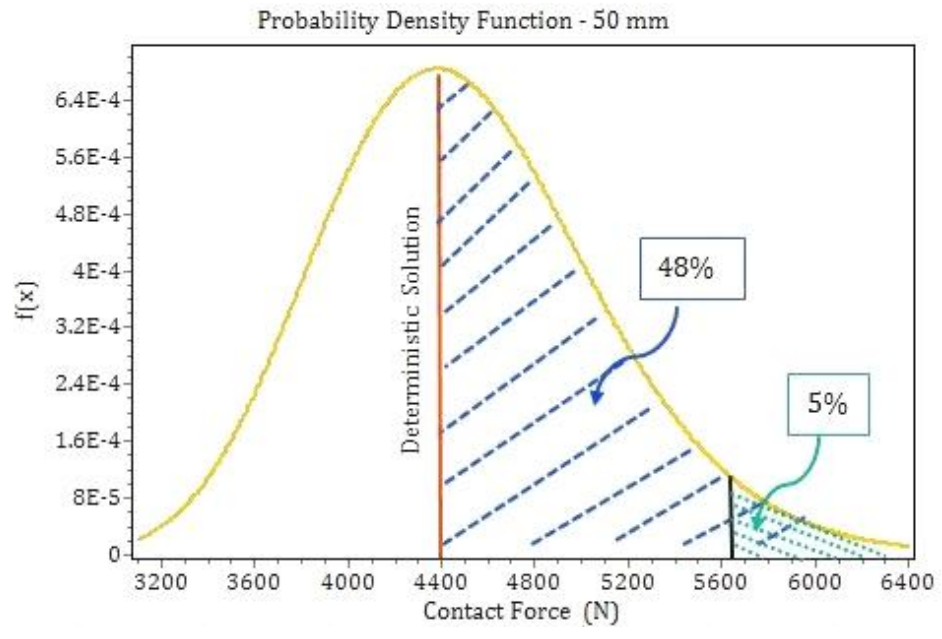

(a) $50 \mathrm{~mm}$

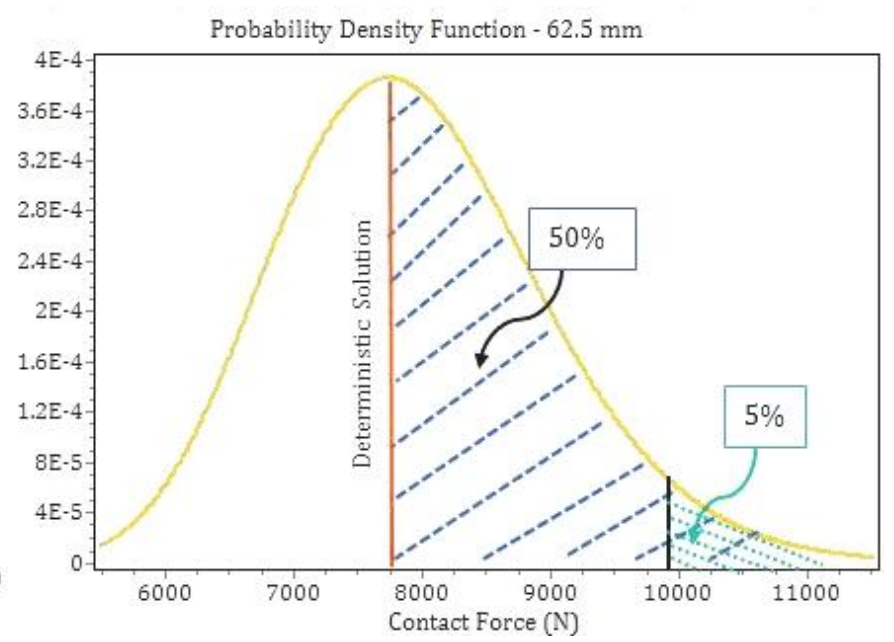

(b) $62.5 \mathrm{~mm}$

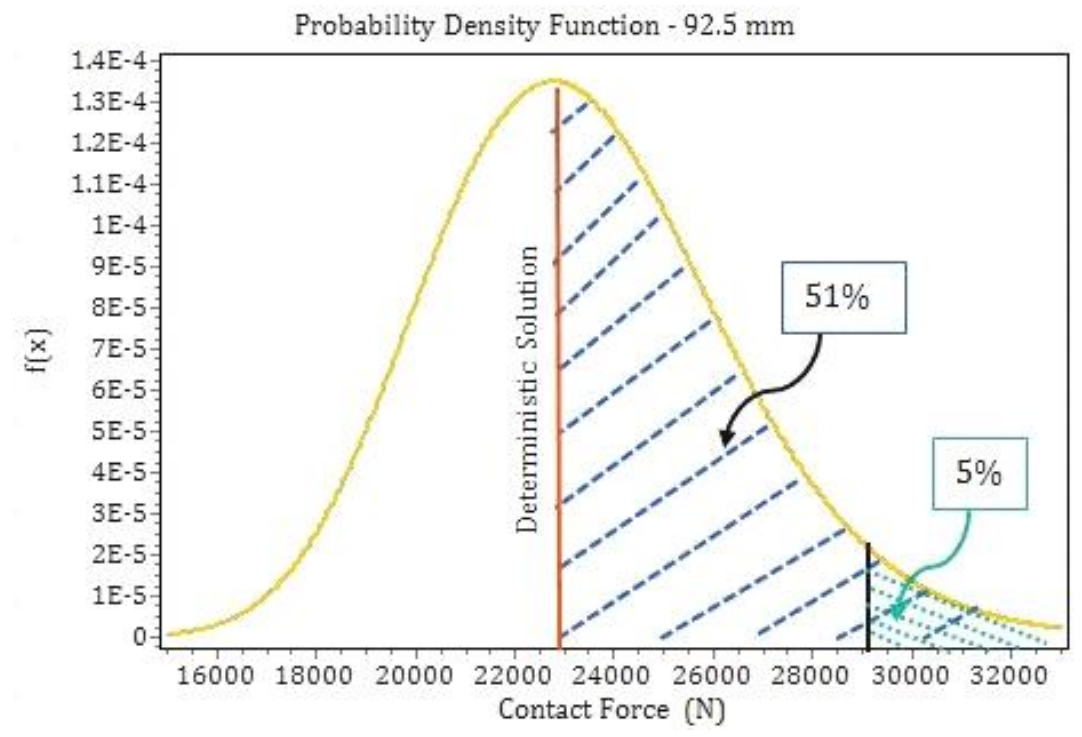

(c) $92.5 \mathrm{~mm}$

Fig. 16 Probability density functions of different size hailstones

\section{Distribution of contact force in a severe category hailstorm}

Data collected from hailstorms in the United states during the period 1989 to 2004 has been analysed to develop a probability density function for size of hailstone $\left(D_{\text {hail }}\right)$ based on an exponential distribution function (Fraile et al. 2003; Shimek et al. 2011). This distribution relationship (of size) was combined with the stochastic model developed in this paper to obtain the probabilistic distribution of the contact force. Five thousand simulations were produced by a stochastic process wherein random numbers of $D_{\text {hail }}, k_{n}, p$, and $C O R$ were first generated using a MATLAB code based on predefined probabilistic distributions that have been presented in Table $1 \&$ Fig. 17. 


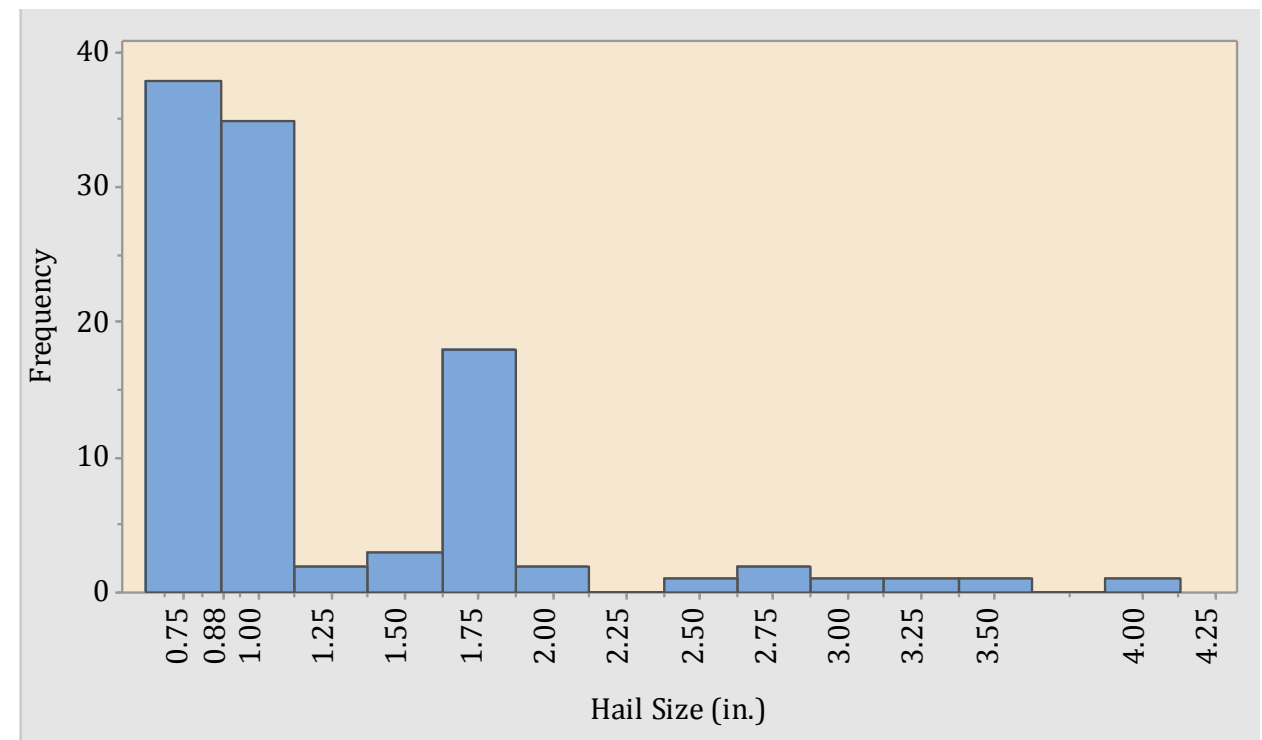

Fig. 17 Distribution of severe hail reports by size (Shimek et al. 2011)

Forcing functions at the point of contact were computed using the algorithm presented in Appendix A for all simulations in which $D_{\text {hail }}$ was in the range $1.8 \mathrm{~cm}-10 \mathrm{~cm}$. Finally, a database comprising the maximum contact force values identified from the individual calculated forcing functions was then developed for a severe category hailstorm. The distribution relationship represented by the developed database was then curve-fitted with a lognormal distribution function and a 3-parameter Weibull distribution function. It is shown that a slightly better match was obtained from the calibrated 3parameter Weibull distribution function (Fig. 18).
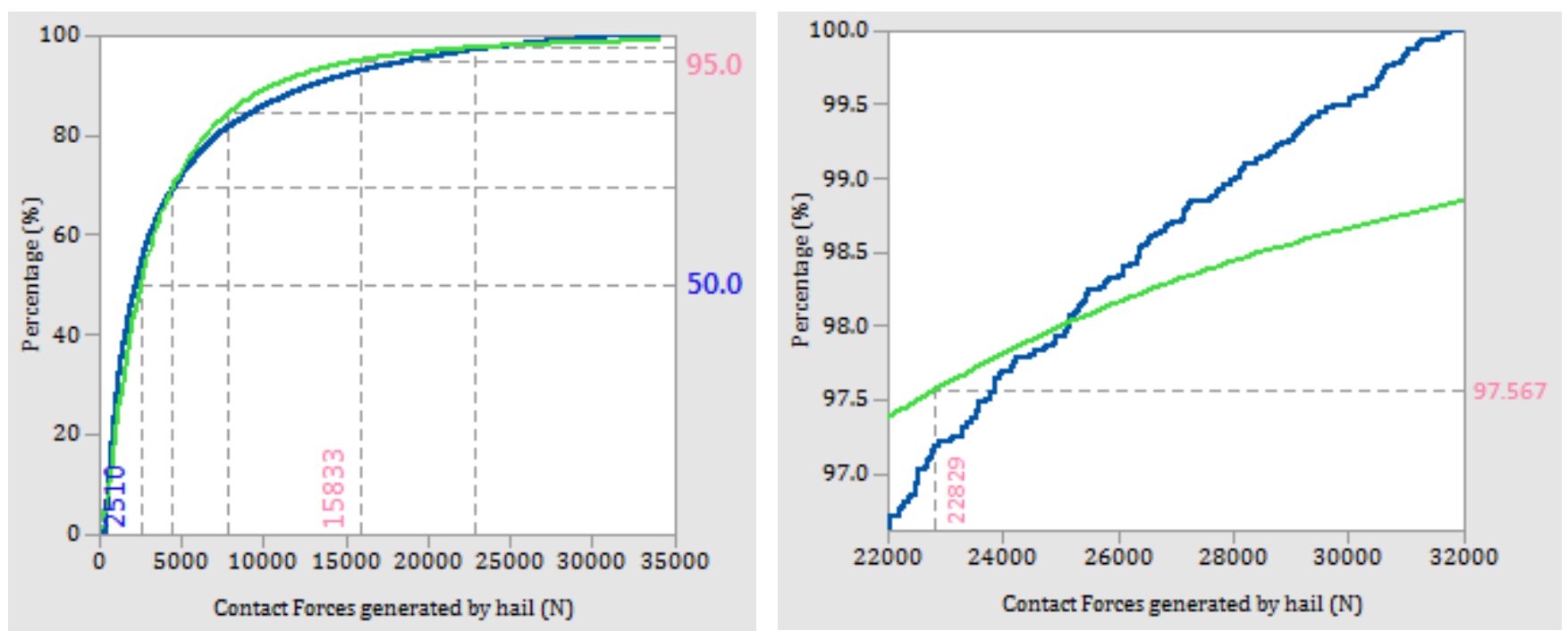

(a) Lognormal Distribution Function 

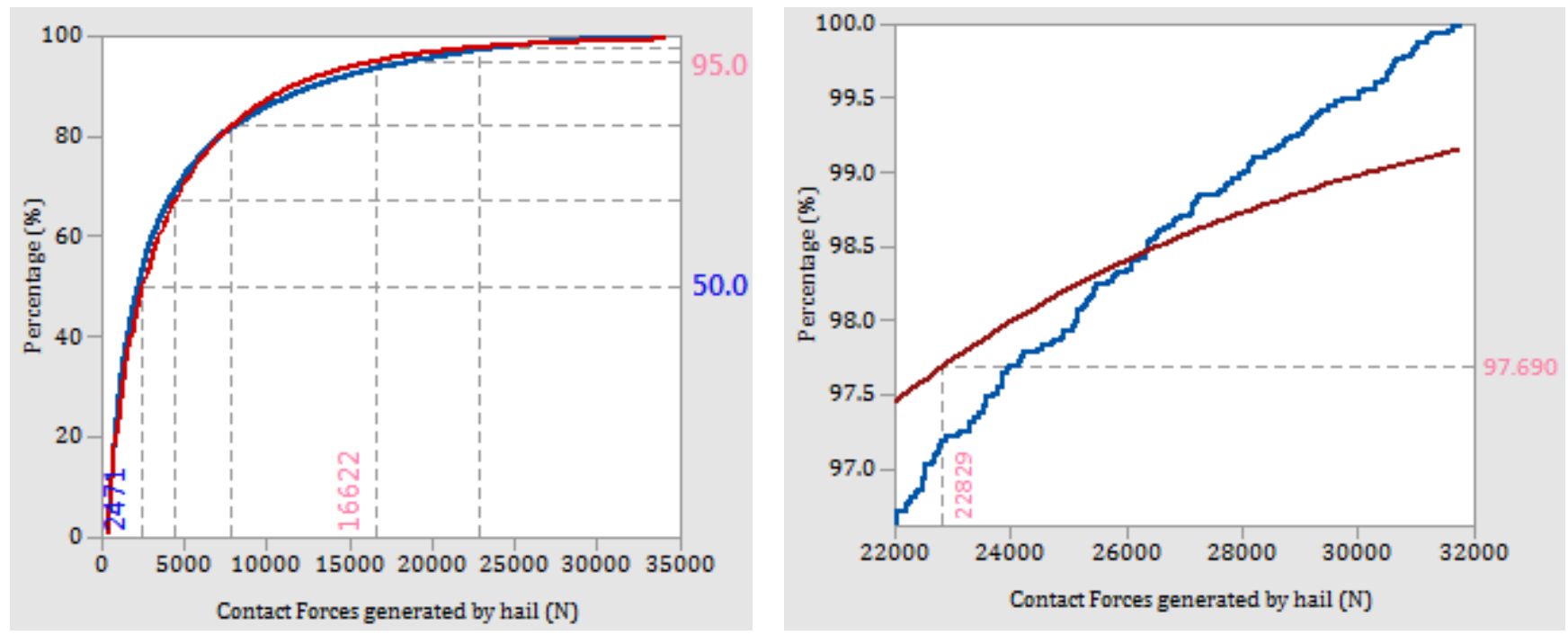

(b) 3- parameter Weibull Distribution Function

— Simulated data — Lognormal Distribution -3-Parameter Weibull Distribution

Fig. $18 \mathrm{CDF}$ curve fitted by Lognormal and Weibull distribution function

The calibrated 3-parameter Weibull distribution function is shown alongside the original simulated values in Fig. 19. In perspectives, an existing probabilistic model showing the distribution of size of hailstones in a severe storm (Fig. 17) has been further developed in this study to produce a probabilistic model showing the distribution of contact force values. The $50^{\text {th }}$ percentile predictions from this newly developed model indicates impact by $40 \mathrm{~mm}$ diameter hailstones and a maximum contact force close to $2.5 \mathrm{kN}$ whereas the $95^{\text {th }}$ percentile predictions corresponds to $83 \mathrm{~mm}$ diameter hailstones and a contact force exceeding $16 \mathrm{kN}$; and the $98^{\text {th }}$ percentile predictions corresponds to $92.5 \mathrm{~mm}$ diameter hailstones and a contact force close to $23 \mathrm{kN}$. These identified contact force values are indicated by the newly developed model to be consistent with the condition of a severe category storm scenario where extensive damage to roofing and cladding materials can occur. Information on the contact force presented herein can be used by manufacturers and designers to re-assess existing products and in making improvements taking into account cost benefits considerations. 


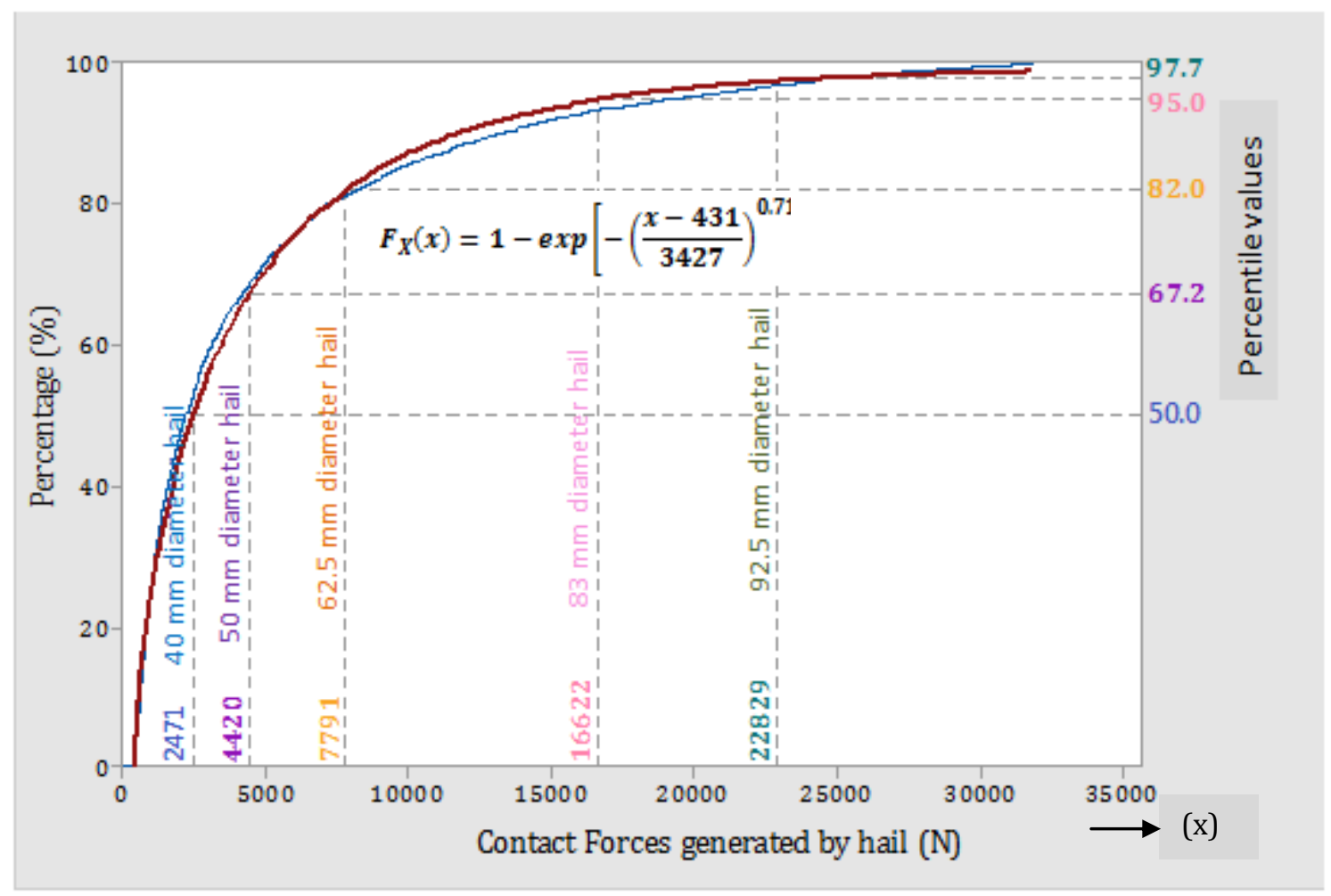

Fig. 19 Stochastic model of contact forces generated by severe category hailstorm

\section{Conclusion}

Contact forces generated by specimens of simulated hail ice (mimicking hailstones) in a series of impact scenarios have been measured using a custom built apparatus. Values of contact forces recorded from impact testing of non-spherical specimens feature wide scatters that were not seen previously from the testing of spherical hail ice specimens. The peak contact force values of impact by spherical and non-spherical specimens (averaged across a large number of tests) have been found to be consistent for a specific mass - velocity combination of impact. An analytical model based on a two-degree-of freedom system (which features the use of the non-linear visco-elastic model to characterise the properties of the fontal spring) was employed for simulating impact actions.

The probabilistic distribution of the modelling parameters: $k_{n}, p$ and $C O R$ was obtained by calibrating against results recorded from impact experiments with spherical and non-spherical hail specimens. A stochastic model which incorporates predictions of the mean values of these parameters along with variations from the mean was then developed. By Monte Carlo simulation (MCS) of the developed stochastic model the probabilistic distribution of the contact force were obtained for a range of impact scenarios. An existing probabilistic model which provides predictions of the distribution of the size of hailstones in a severe category hailstorm was further developed into a chart (Fig. 19) showing the probabilistic distribution of the maximum contact force. Information on the contact force presented in 
this article can be used by manufacturers and designers to re-assess existing products and in making improvements taking into account cost benefits considerations.

Appendix A - Time-Step integration algorithm for solving Non-linear Visco-elastic 2DOF Massspring-damper System Model

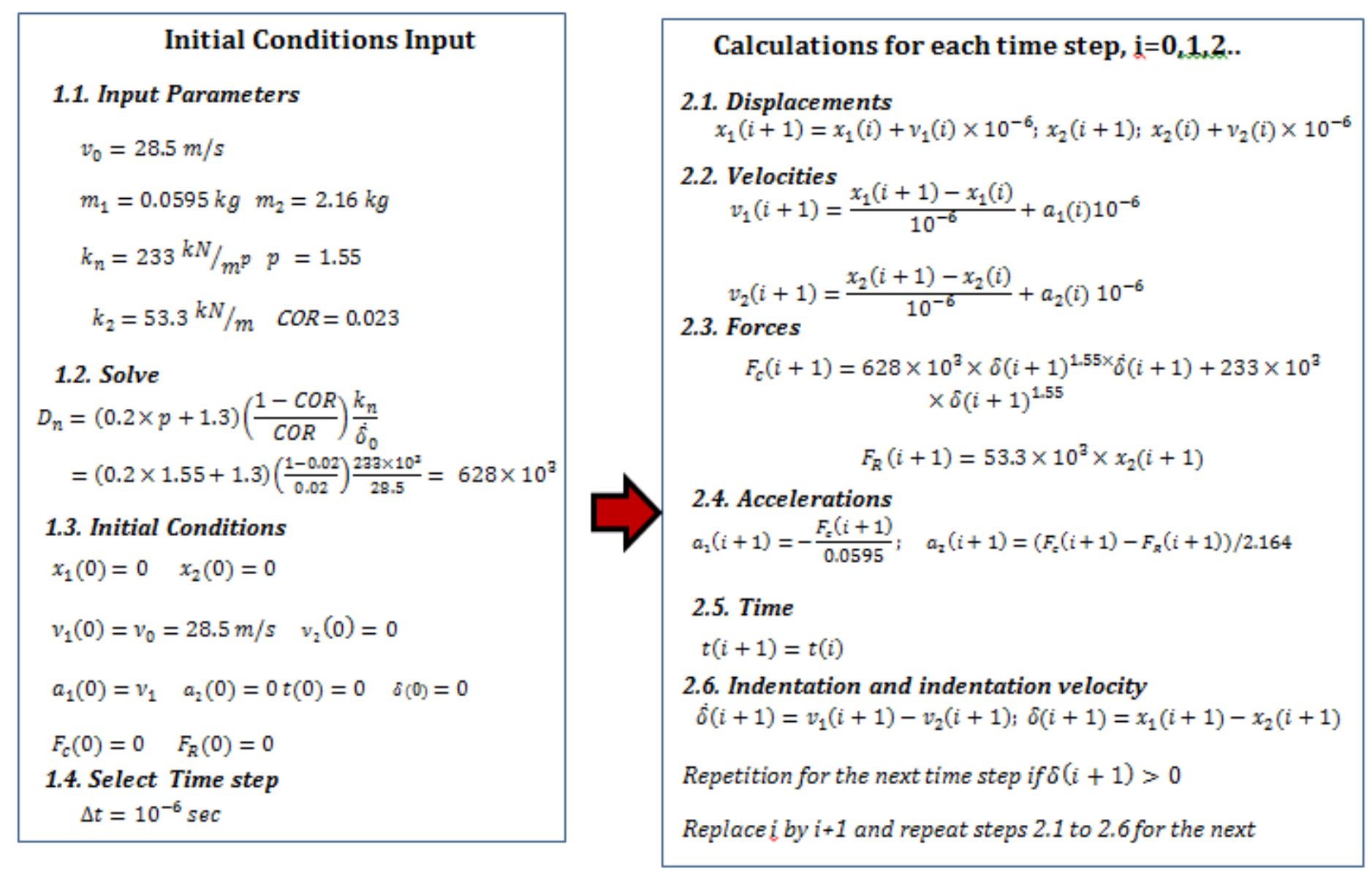

Fig. A1 Summary of time-step integration algorithm for contact phase 


\section{Initial Conditions Input}

\subsection{Input Parameters}

$$
m_{2}=2.164 \mathrm{~kg} ; k_{2}=53.3^{\mathrm{kN}} / \mathrm{m}
$$

$\xi_{2}=5 \%$ is assumed

\subsection{Solve}

$$
w_{2}=\sqrt{\frac{k_{2}}{m_{2}}}=\sqrt{\frac{53.3 \times 10^{3}}{2.164}}=157 \mathrm{rad} / \mathrm{s}
$$

\subsection{Initial Conditions}

$$
\begin{gathered}
t(0)=t_{c} \\
x_{s 1}(0)=x_{1, t_{c}} ; x_{s 2}(0)=x_{2, t_{c}} \\
F_{R}(0)=F_{R, t_{c}}
\end{gathered}
$$

\subsection{Select Time step}

$$
\Delta t=10^{-6} \mathrm{sec}
$$

\section{Calculations for each time step, $\mathrm{j}=0,1,2$}

\subsection{Time}

$t(j+1)=t(j)$

2.2. Solve

$$
\begin{gathered}
x_{s 1}(j+1)=x_{1, t_{c}}+\left(t(j+1)-t_{c}\right) \times v_{1, t_{c}} \\
x_{s 2}(j+1)=e^{-0.05 \times 157 \times\left[t(j+1)-t_{d}\right.}\left(x_{2, t_{c}} \cos \left\{157 \times\left[t(j+1)-t_{c}\right]\right\}\right. \\
\left.+\frac{v_{2, t_{c}}}{157} \sin \left\{157 \times\left[t(j+1)-t_{c}\right]\right\}\right)
\end{gathered}
$$

\subsection{Reaction Force}

$$
F_{R}(j+1)=53.3 \times 10^{3} \times x_{s 2}(j+1)
$$

Repetition for the next time step

Replace $j$ by $j+1$ and repeat steps 2.1 to 2.3 for the next time step.

Fig.A2 Summary of time-step integration algorithm for separation phase

Table A1 Numerical Solution of 2DOF system model solved by time step integration method in EXCEL for $50 \mathrm{~mm}$ hail impacting at $28.5 \mathrm{~m} / \mathrm{s}$ (results listed have been used in the plotting of Fig. 3)

\begin{tabular}{cccccccccccc}
\hline $\mathbf{i}$ & $\begin{array}{c}\boldsymbol{t}_{\boldsymbol{c}} \\
(\mathbf{s})\end{array}$ & $\begin{array}{c}\boldsymbol{v}_{\boldsymbol{1}} \\
(\mathbf{m} / \mathbf{s})\end{array}$ & $\begin{array}{c}\boldsymbol{v}_{2} \\
(\mathbf{m} / \mathbf{s})\end{array}$ & $\begin{array}{c}\boldsymbol{x}_{\boldsymbol{1}} \\
(\mathbf{m})\end{array}$ & $\begin{array}{c}\boldsymbol{x}_{2} \\
(\mathbf{m})\end{array}$ & $\begin{array}{c}\boldsymbol{\delta} \\
(\mathbf{m})\end{array}$ & $\begin{array}{c}\dot{\boldsymbol{\delta}} \\
(\mathbf{m} / \mathbf{s})\end{array}$ & $\begin{array}{c}\boldsymbol{a}_{\boldsymbol{1}} \\
\left(\mathbf{m} / \mathbf{s}^{2}\right)\end{array}$ & $\begin{array}{c}\boldsymbol{a}_{2} \\
\left(\mathbf{m} / \mathbf{s}^{2}\right)\end{array}$ & $\begin{array}{c}\boldsymbol{F}_{\boldsymbol{c}} \\
(\mathbf{N})\end{array}$ & $\begin{array}{c}\boldsymbol{F}_{\boldsymbol{R}} \\
(\mathbf{N})\end{array}$ \\
\hline 0 & 0.000 & 28.500 & 0.000 & 0.000 & 0.000 & 0.000 & 0.000 & 0.000 & 0.000 & 0.000 & 0.000 \\
1 & 0.000 & 28.500 & 0.000 & 0.000 & 0.000 & 0.000 & 28.500 & -21.880 & 0.602 & 1.302 & 0.000 \\
2 & 0.000 & 28.500 & 0.000 & 0.000 & 0.000 & 0.000 & 28.500 & -65.414 & 1.799 & 3.892 & 0.000 \\
3 & 0.000 & 28.500 & 0.000 & 0.000 & 0.000 & 0.000 & 28.500 & -124.135 & 3.413 & 7.386 & 0.000 \\
4 & 0.000 & 28.500 & 0.000 & 0.000 & 0.000 & 0.000 & 28.500 & -195.566 & 5.377 & 11.636 & 0.000 \\
5 & 0.000 & 28.500 & 0.000 & 0.000 & 0.000 & 0.000 & 28.500 & -278.232 & 7.650 & 16.555 & 0.000 \\
. &. &. &. &. &. &. &. &. &. &. &. \\
. &. &. &. &. &. &. &. &. &. &. &. \\
1609 & 0.002 & 0.401 & 0.757 & 0.010 & 0.001 & 0.009 & -0.356 & -30.143 & -23.196 & 1.794 & 51.990 \\
1610 & 0.002 & 0.401 & 0.757 & 0.010 & 0.001 & 0.009 & -0.356 & -30.093 & -23.216 & 1.791 & 52.030 \\
1611 & 0.002 & 0.401 & 0.757 & 0.010 & 0.001 & 0.009 & -0.356 & -30.043 & -23.236 & 1.788 & 52.071 \\
1612 & 0.002 & 0.401 & 0.757 & 0.010 & 0.001 & 0.009 & -0.356 & -29.994 & -23.256 & 1.785 & 52.111 \\
1613 & 0.002 & 0.401 & 0.757 & 0.010 & 0.001 & 0.009 & -0.356 & -29.946 & -23.276 & 1.782 & 52.151 \\
\hline
\end{tabular}




\section{Appendix B}

The values of peak contact force generated by spherical SHI and non-spherical SHI specimens at that particular impact velocity were first measured using the custom-made measuring device. The mean value of the peak contact force for spherical SHI specimens (shown in Table B1) was then calculated based on averaging the test results across ten number of spherical SHI specimens. For non-spherical SHI specimens, the average value of the peak contact force was obtained based on averaging the test results of at least 30 number of non-spherical SHI specimens impacting onto the target at that specific velocity.

Table B1. Experimental measurement of contact forces generated by the impact of different shapes of SHI at different impact velocities

\begin{tabular}{ccccc}
\hline \multirow{2}{*}{ Impactor Specimen } & \multicolumn{2}{c}{ Impact Velocity $(\mathrm{m} / \mathrm{s})$} & \multicolumn{2}{c}{ Peak Contact } \\
\cline { 2 - 5 } & Mean & Std & Mean & Std \\
\hline \multirow{4}{*}{ Spherical Specimens } & 25.5 & 0.918 & 4,273 & 109.5 \\
& 30.7 & 0.801 & 5,410 & 105.8 \\
& 35.3 & 0.819 & 6,122 & 215.6 \\
& 40.4 & 0.813 & 7,737 & 276.1 \\
& 45.5 & 0.897 & 10,045 & 397.1 \\
\hline \multirow{3}{*}{ Non-spherical Specimens } & 25.7 & 0.972 & 4,239 & 994.8 \\
& 30.5 & 0.742 & 5,283 & 937.8 \\
& 36.0 & 0.978 & 6,154 & $1,028.9$ \\
& 39.8 & 0.983 & 7,709 & $1,116.4$ \\
& 45.4 & 0.949 & 9,934 & 1,716 \\
\hline
\end{tabular}




\section{References}

Anghileri M, Castelletti L-ML, Invernizzi F, Mascheroni M (2005) A survey of numerical models for hail impact analysis using explicit finite element codes International Journal of Impact Engineering 31:929-944 doi:http://dx.doi.org/10.1016/j.ijimpeng.2004.06.009

ANSI FM 4473 -Test Standard for Impact Resistance American National Standard Institute 2011, Washington

Appleby-Thomas GJ, Hazell PJ, Dahini G (2011) On the response of two commercially-important CFRP structures to multiple ice impacts Composite Structures 93:2619-2627 doi:http://dx.doi.org/10.1016/j.compstruct.2011.04.029

Combescure A, Chuzel-Marmot Y, Fabis J (2011) Experimental study of high-velocity impact and fracture of ice International Journal of Solids and Structures 48:2779-2790 doi:http://dx.doi.org/10.1016/j.ijsolstr.2011.05.028

Flueler P (2009) Hail Impact Resistance of Building Materials. Istanbul Technical University, Istanbul,Turkey. http://www.rci-online.org/interface/2009-09-flueler.pdf/ on 13 June 2014.

Fraile R, Castro A, López L, Sánchez JL, Palencia C (2003) The influence of melting on hailstone size distribution Atmospheric Research 67-68:203-213 doi:http://dx.doi.org/10.1016/S0169$\underline{8095(03) 00052-8}$

Gessler S, Petty SE (2013) Hail Fundamentals and General Hail-Strike Damage Assessment Methodology. Forensic engineering. [electronic resource] : damage assessments for residential and commercial structures. Boca Raton, Fla. : CRC Press, Taylor \& Francis Group,

Kim H, Kedward KT (2000) Modeling Hail Ice Impacts and Predicting Impact Damage Initiation in Composite Structures AIAA Journal 38:1278-1288 doi:10.2514/2.1099

Kim H, Kim D, Welch K, Kedward (2003) Experimental investigation of high velocity ice impacts on woven carbon/epoxy composite panels Composites Part A, Applied science and manufacturing 34:25-41

Lam N, Tsang HH, Gad EF (2009) Simulation of Response to Low Velocity Impact by Spreadsheet Structural stability and Dynamics 10:9 doi:10.1142/S0219455410003580

Marshall TP, Herzog RF, Morrison SJ, Smith SR (2004) Hail damage to tile Roofing. Paper presented at the 22nd conference on Severe Local Storms, 2004 October 6

Matson RJ, Huggins AW (1980) The Direct Measurement of the Sizes, Shapes and Kinematics of Falling Hailstones Journal of the Atmospheric Sciences 37:1107-1125 doi:10.1175/15200469(1980)037<1107:TDMOTS>2.0.CO;2

Olsson R, Juntikka R, Asp LE (2013) High Velocity Hail Impact on Composite Laminates Modelling and Testing. In: Abrate S, Castanié B, Rajapakse SYD (eds) Dynamic Failure of Composite and Sandwich Structures. Springer Netherlands, Dordrecht, pp 393-426. doi:10.1007/978-94-007-5329-7_9 
Park H, Kim (2010) Damage resistance of single lap adhesive composite joints by transverse ice impact International journal of impact engineering 37:177-184

Paterson DA, Sankaran R (1994) Hail impact on building envelopes Journal of Wind Engineering and Industrial Aerodynamics 53:229-246 doi:http://dx.doi.org/10.1016/0167-6105(94)90028-0

Perera S, Lam N, Pathirana M, Zhang L, Ruan D, Gad E (2016) Deterministic solutions for contact force generated by impact of windborne debris International Journal of Impact Engineering 91:126-141 doi:http://dx.doi.org/10.1016/j.ijimpeng.2016.01.002

Sharafi P, Teh LH, Hadi MN (2013) Theory based sensitivity analysis and damage detection of steel roof sheeting for hailstone impact. In: Topics in Dynamics of Civil Structures, Volume 4. Springer, pp 243-252

Shimek E, Ekwaro-Osire S, Rasty J Probabilistic Analysis of Steel Roof Damage From Hail Strike. In: ASME 2011 International Mechanical Engineering Congress and Exposition, 2011. American Society of Mechanical Engineers, pp 503-510

Sun J, Lam N, Zhang L, Ruan D, Gad E (2015) Contact forces generated by hailstone impact International Journal of Impact Engineering 84:145-158 doi:http://dx.doi.org/10.1016/j.ijimpeng.2015.05.015

Tippmann J, Kim H, Rhymer J (2013) Experimentally validated strain rate dependent material model for spherical ice impact simulation International journal of impact engineering 57:43-54

Yang Y, Lam N, Zhang L (2012a) Estimation of Response of Plate Structure Subject to Low Velocity impact by a Solid Object International Journal of Structural Stability and Dynamics 12:1250053 doi:10.1142/S0219455412500538

Yang Y, Lam N, Zhang L (2012b) Evaluation of simplified methods of estimating beam responses to impact International Journal of Structural Stability and Dynamics 12 doi:http://dx.doi.org/10.1142/S0219455412500162 


\section{University Library}

\section{- M M I E R R V A gateway to Melbourne's research publications}

Minerva Access is the Institutional Repository of The University of Melbourne

Author/s:

Perera, S;Lam, N;Pathirana, M;Zhang, L;Ruan, D;Gad, E

Title:

Probabilistic modelling of forces of hail

Date:

2018-03-01

Citation:

Perera, S., Lam, N., Pathirana, M., Zhang, L., Ruan, D. \& Gad, E. (2018). Probabilistic modelling of forces of hail. NATURAL HAZARDS, 91 (1), pp.133-153. https:// doi.org/10.1007/s11069-017-3117-7.

Persistent Link:

http://hdl.handle.net/11343/282782 